\title{
Enteroparasitoses em escolares do Nordeste brasileiro: Uma revisão bibliográfica
}

\author{
Enteroparasitosis in school children from Northeastern Brazill: A bibliographic review \\ Enteroparasitosis em escolares del Nordeste brasileño: Uma revisión bibliográfica
}

Recebido:23/06/2021 | Revisado: 29/06/2021 | Aceito: 30/06/2021 | Publicado: 13/07/2021

\author{
Caroline Cruvinel de Souza \\ ORCID: https://orcid.org/0000-0002-4636-5641 \\ Universidade Federal do Vale do São Francisco, Brasil \\ E-mail: cruvinelcaroline@gmail.com \\ Adson Aragão de Araújo Santos \\ ORCID: https://orcid.org/0000-0003-2967-9486 \\ Universidade Federal do Vale do São Francisco, Brasil \\ E-mail: adsonaragao10@gmail.com \\ Eduardo Raimundo Ramos dos Santos Júnior \\ ORCID: https://orcid.org/0000-0001-6612-598X \\ Universidade Federal do Vale do São Francisco, Brasil \\ E-mail: Eduardo.ramos@discente.univasf.edu.br \\ Hellen de Carvalho Lima \\ ORCID: https://orcid.org/0000-0002-4708-1499 \\ Universidade Federal do Vale do São Francisco, Brasil \\ E-mail: hellendc.lima@gmail.com \\ Anekécia Lauro da Silva \\ ORCID: https://orcid.org/0000-0003-2778-1460 \\ Universidade Federal do Vale do São Francisco, Brasil \\ E-mail: anekecia@gmail.com \\ Diogo Vilar da Fonsêca \\ ORCID: https://orcid.org/0000-0001-7869-7061 \\ Universidade Federal do Vale do São Francisco, Brasil \\ E-mail: diogo.vilar@univasf.edu.br
}

\begin{abstract}
Resumo
As enteroparasitoses constituem um sério problema de saúde pública em razão do elevado número de pessoas acometidas e das alterações orgânicas que podem ser causadas. Atingem indivíduos de todas as faixas etárias, mas principalmente as crianças em idade escolar. Assim, o objetivo consiste em construir uma revisão bibliográfica sobre enteroparasitismo em crianças no Nordeste Brasileiro entre os anos de 2015 a 2020. A pesquisa é do tipo descritiva e qualitativa, cujo material foi oriundo dos resultados encontrados nas bases de dados da Biblioteca Virtual de Saúde e Google Acadêmico. Foram encontrados 160 estudos. Após aplicados os critérios de inclusão e exclusão, analisaram-se 37 artigos, sendo 1 do estado de Alagoas, 1 do Sergipe, 1 do Rio Grande do Norte, 2 do Pernambuco, 4 da Bahia, 5 do Piauí, 7 do Ceará, 8 da Paraíba e 8 do Maranhão. Foi possível constatar que a prevalência de enteroparasitoses em crianças ainda é um problema no Nordeste brasileiro e permanece alta, indicando dificuldades no acesso à educação sanitária e no controle das infecções. Dessa maneira, fica evidente a necessidade de medidas que diminuam ou até eliminem processos de infecções, como ações profiláticas e atividades educativas em saúde.
\end{abstract}

Palavras-chave: Doenças parasitárias; Saúde da criança; Intestinos.

\begin{abstract}
Enteroparasitosis is a serious public health problem due to the high number of people affected and the organic changes that can be caused. They affect individuals of all age groups, but mainly school children. Thereby, the objective is to build a bibliographic review on enteroparasitism in children in Northeast Brazil between the years 2015 to 2020. The research is descriptive and qualitative, whose material came from the results found in the databases of the Virtual Health Library and Google Scholar. 160 studies were found. After applying the inclusion and exclusion criteria, 37 articles were analyzed, 1 from Alagoas, 1 from Sergipe, 1 from Rio Grande do Norte, 2 from Pernambuco, 4 from Bahia, 5 from Piauí, 7 from Ceará, 8 from Paraíba and 8 from Maranhão. It was possible to verify that the prevalence of enteroparasitosis in children is still a problem in Northeast Brazil and remains high, indicating difficulties in accessing health education and in controlling infections. Therefore, it is evident the need for measures that reduce or even eliminate infection processes, such as prophylactic actions and educational activities in health.
\end{abstract}

Keywords: Parasitic diseases; Child health; Intestines. 


\begin{abstract}
Resumen
Las enteroparasitosis constituyen un grave problema de salud pública debido al gran número de personas afectadas y a la producción de posibles cambios orgánicos. Afectan a personas de todas las edades, pero sobre todo a los niños en edad escolar. Así, el objetivo consiste en construir una revisión bibliográfica sobre enteroparasitismo en niños en el Nordeste Brasileño entre los años 2015 y 2020/ de 2015 al 2020. La búsqueda es de tipo descriptivo y cualitativo, cuyo material resultó de la investigación en las bases de datos de la Biblioteca Virtual de Salud y Google Académico. Se encontraron 160 estudios. Después de aplicar los criterios de inclusión y exclusión, se analizaron 37 artículos, siendo 1 del estado de Alagoas, 1 de Sergipe, 1 de Río Grande do Norte, 2 de Pernambuco, 4 de Bahía, 5 de Piaú, 7 de Ceará, 8 de Paraíba y 8 de Maranhão. Fue posible constatar que la prevalencia de enteroparasitosis en niños todavía es un problema en el Nordeste brasileño y se mantiene alta, indicando dificultades en el acceso a la educación sanitaria y en el control de las infecciones. De esta manera, resulta patente la necesidad de medidas que disminuyan o incluso eliminen procesos de infecciones, como acciones profilácticas y actividades educativas en salud.
\end{abstract}

Palabras clave: Enfermedades parasitarias; Salud del niño; Intestinos.

\title{
1. Introdução
}

As enteroparasitoses constituem um sério problema de saúde pública em razão do elevado número de pessoas acometidas e das alterações orgânicas que podem ser causadas. As condições socioeconômicas e higiênico-sanitárias são importantes na contribuição para a alta prevalência no Brasil. Acometem indivíduos de todas as faixas etárias, mas principalmente as crianças em idade escolar. Essas enfermidades prejudicam a absorção de nutrientes e podem ser responsáveis pelo baixo crescimento, contudo as crianças desnutridas podem ter pior prognóstico (Silva, Silva, Almeida, Sousa \& Freitas, 2009).

As helmintíases e protozooses são as doenças mais comuns em todo o mundo. São endêmicas em países em desenvolvimento e nesses locais constituem problemas de saúde pública. Os nematelmintos mais comuns são o Ascaris lumbricoides, o Trichuristrichiura, o Strongyloides stercoralis e os ancilostomídeos. Já os protozoários mais comuns são a Giardia lamblia e Entamoeba histolytica/díspar (Brasil, 2005).

Um estudo realizado em $2012 \mathrm{fez}$ um levantamento do quadro de prevalência de parasitas intestinais em crianças no período escolar de diversas cidades brasileiras no período de março de 2009 a novembro de 2010, e verificou-se que a média as prevalências encontradas nas diferentes regiões do Brasil foram de $65 \%$ na região Norte, $62 \%$ na região Nordeste, $51 \%$ na região Sul, $49 \%$ no Centro-Oeste e 30\% de positividade no Sudeste, evidenciando as discrepâncias entre as regiões do país (Menezes, Medeiros \& Dani, 2012).

De fato, as crianças em idade pré-escolar, 0 a 3 anos e escolar, 4 a 12 anos, são as mais acometidas em virtude de terem o costume de levar as mãos sujas à boca, não possuírem o hábito de lavá-las frequentemente e seus sistemas imunológicos ainda são imaturos. Em consequência disso, as enteroparasitoses encontram nelas o local ideal para se proliferarem e, essas, apresentam os quadros clínicos mais expressivos, com deficiências nutricionais devido à espoliação dos parasitos, o que gera prejuízo do desenvolvimento (World Health Organization, 2017). As doenças parasitárias geralmente se apresentam assintomáticas, porém, quando são clinicamente ativas, podem gerar obstrução intestinal, desnutrição, anemia por deficiência de ferro e quadros expressivos de diarreia e má absorção (Furtado \& Melo, 2011).

A forma mais comum de transmissão das parasitoses intestinais é a via oral-fecal através de água e alimentos contaminados com cistos e/ou ovos. As estratégias profiláticas delineadas pela Organização Mundial de Saúde (OMS) consistem no tratamento farmacológico dos infectados para interromper a transmissão; desparasitação anual em zonas endêmicas; educação em saúde explicitando o manuseio correto dos alimentos, sua preparação e conservação, principalmente com as crianças; controle rigoroso das águas de consumo, sendo tratada, filtrada ou fervida; o acesso às boas condições de higiene e saneamento básico; tratamento do esgoto e o incentivo ao uso de calçados para evitar algumas das infecções (Brasil, 2010; Grott, Hartmann, Franco \& Goulart, 2016; Nicoli, Kunzendorff, Luz, Martins \& Randow, 2018; Pedroso \& Amarante, 2006; Vaz, 2014; Weber et al., 2012). 
Uma vez que as crianças dependem de cuidados de outras pessoas e possuem outros agravos, isso as torna mais suscetíveis às parasitoses (Mylius et al., 2003). A aglomeração de crianças em creches e escolas leva, também, ao maior índice de parasitoses nessas faixas etárias pela facilidade de contaminação e disseminação (Monteiro et al., 2009; Zaiden, Santos, Cano \& Nascif, 2008). Assim, o objetivo deste artigo é construir uma revisão bibliográfica sobre enteroparasitoses em crianças no Nordeste Brasileiro em estudos publicados entre os anos de 2015 e 2020.

\section{Metodologia}

A pesquisa é do tipo descritiva com análise qualitativa de dados (Souza, 2019), cujo material foi oriundo dos resultados encontrados em pesquisas feitas nas bases de dados da Biblioteca Virtual de Saúde (BVS) e Google Acadêmico com publicações entre os anos de 2015 e 2020. A busca foi feita utilizando-se uma combinação dos descritores: "prevalência" AND "parasitoses intestinais" AND "escolares" OR "crianças" em qualquer parte do texto associado a nomes de cidades e/ou estados do Nordeste Brasileiro no título, sendo os demais excluídos da análise. A elegibilidade do material consistia no atendimento a critérios de inclusão: artigo científico publicado em português; artigos de acesso livre, além de manuscritos originais, verificados após leitura do resumo e delimitação do estudo. Quanto aos critérios de exclusão, foram eliminados todos os Trabalhos de Conclusão de Curso, Dissertações, Teses, artigos científicos repetidos e revisões bibliográficas.

Assim, foram encontrados 2 artigos na plataforma BVS e 158 arquivos científicos no Google Acadêmico. Após aplicados os devidos critérios, foram analisados 37 artigos no total, como descrito na Figura 1. Sendo 1 do estado de Alagoas, 1 do Sergipe, 1 do Rio Grande do Norte, 2 do Pernambuco, 4 da Bahia, 5 do Piauí, 7 do Ceará, 8 da Paraíba e 8 do Maranhão, como na Figura 1.

Figura 1: Organograma dos artigos selecionados.

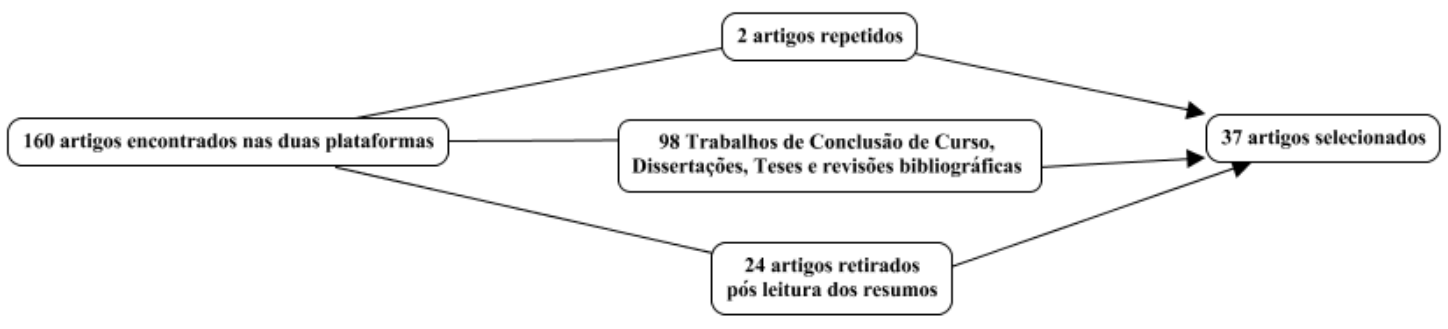

Fonte: Autores.

A elegibilidade do material consistia no atendimento a critérios de inclusão: artigo científico publicado em português; artigos de acesso livre, além de manuscritos originais, verificados após leitura do resumo e delimitação do estudo. Quanto aos critérios de exclusão, foram eliminados todos os Trabalhos de Conclusão de Curso, Dissertações, Teses, artigos científicos repetidos e revisões bibliográficas.

\section{Resultados}

Os dados foram analisados por estado da região Nordeste com autores, ano de publicação, objetivo do estudo, público alvo, principais parasitos, prevalência e método utilizado; características dispostas no Quadro 1 abaixo. 
Quadro 1: Relação dos principais dados dos artigos.

\begin{tabular}{|c|c|c|c|c|c|c|}
\hline Estado & $\begin{array}{l}\text { Referência } \\
\quad \text { (ano) }\end{array}$ & Objetivo & Público alvo & $\begin{array}{c}\text { Principais } \\
\text { Parasitos }\end{array}$ & $\begin{array}{l}\text { Prevalência } \\
\text { geral de } \\
\text { parasitoses } \\
(\%)\end{array}$ & Método \\
\hline Bahia & $\begin{array}{l}\text { Carvalho et } \\
\text { al. }(2016)\end{array}$ & $\begin{array}{c}\text { Determinar a } \\
\text { prevalência dos } \\
\text { enteroparasitos } \\
\text { correlacionando-a } \\
\text { com fatores de risco } \\
\text { e doenças alérgicas } \\
\text { em crianças e } \\
\text { adolescentes } \\
\text { residentes no } \\
\text { município de Santo } \\
\text { Antônio de Jesus - } \\
\text { Bahia - Brasil. }\end{array}$ & $\begin{array}{l}0-18 \text { anos, sendo } \\
156 \text { participantes }\end{array}$ & $\begin{array}{c}\text { FREQUÊNCIA } \\
\text { Endolimax nana }(\mathrm{n}=81), \\
\text { Entamoeba coli }(\mathrm{n}=36), \\
\text { Enterobius vermicularis } \\
(\mathrm{n}=31), \text { Trichuris trichiura } \\
(\mathrm{n}=26), \text { Giardia lamblia } \\
(\mathrm{n}=17) \text {, Ascaris lumbricoides } \\
(\mathrm{n}=15), \text { Entamoeba histolytica } \\
(\mathrm{n}=12), \text { Strongyloides } \\
\text { stercoralis }(\mathrm{n}=7), \\
\text { ancilostomídeos }(\mathrm{n}=5), \\
\text { Hymenolepis nana }(\mathrm{n}=2), \\
\text { Taenia sp }(\mathrm{n}=1), \text { Schistosoma } \\
\text { mansoni }(\mathrm{n}=1) \text { e Iodamoeba } \\
\text { butschlii }(\mathrm{n}=1)\end{array}$ & $75,0 \%$ & $\begin{array}{c}\text { Sedimentação } \\
\text { espontânea; } \\
\text { Kato-Katz; } \\
\text { Faust; } \\
\text { Fita adesiva; } \\
\text { Rugai. }\end{array}$ \\
\hline Bahia & $\begin{array}{l}\text { Lazzari et } \\
\text { al. }(2019)\end{array}$ & $\begin{array}{l}\text { Avaliar a prevalência } \\
\text { de infecção por } \\
\text { enteroparasitoses no } \\
\text { município de Luis } \\
\text { Eduardo Magalhães - } \\
\text { BA. }\end{array}$ & $\begin{array}{l}\text { Prontuários de } \\
\text { pacientes } \\
\text { atendidos pelo } \\
\text { LACEN, sendo } \\
584 \text { no total }\end{array}$ & $\begin{array}{c}\text { Endolimax nana }(40,4 \%), \\
\text { Entamoeba coli }(38,9 \%), \\
\text { Giardia lamblia }(23,5 \%), \\
\text { Entamoeba histolytica }(8,8 \%) .\end{array}$ & $23,2 \%$ & $\begin{array}{l}\text { Método não } \\
\text { informado. }\end{array}$ \\
\hline Bahia & $\begin{array}{l}\text { Glier } \text { et al. } \\
\text { (2019) }\end{array}$ & $\begin{array}{c}\text { Determinar a } \\
\text { prevalência de } \\
\text { enteroparasitoses em } \\
\text { crianças assistidas } \\
\text { por uma Organização } \\
\text { não Governamental } \\
\text { (ONG) do município } \\
\text { de Barreiras estado } \\
\text { da Bahia e servir } \\
\text { como guia na } \\
\text { condução, tratamento } \\
\text { e fornecimento de } \\
\text { dados que } \\
\text { possibilitem corrigir } \\
\text { deficiências e } \\
\text { desenvolver } \\
\text { programas de } \\
\text { profilaxia. }\end{array}$ & $\begin{array}{l}3 \text { a } 5 \text { anos, sendo } \\
76 \text { participantes }\end{array}$ & $\begin{array}{c}\text { Entamoeba coli }(41,0 \%), \\
\text { Entamoeba histolytica } \\
(25,0 \%), \\
\text { Giardia lamblia }(10,0 \%), \\
\text { Endolimax nana }(9,0 \%), \\
\text { Iodamoeba butschilii }(9,0 \%), \\
\text { Ascaris lumbricoides }(6,6 \%) \\
\text { Poliparasitose }(68,0 \%) .\end{array}$ & $54,0 \%$ & $\begin{array}{l}\text { Sedimentação } \\
\text { por inversão } \\
\text { com dupla } \\
\text { filtração. }\end{array}$ \\
\hline Bahia & $\begin{array}{l}\text { Rosine, } \\
\text { Rosine, } \\
\text { Ribeiro \& } \\
\text { Schröder } \\
\text { (2018) }\end{array}$ & $\begin{array}{c}\text { Investigar a } \\
\text { prevalência das } \\
\text { parasitoses intestinais } \\
\text { na Comunidade } \\
\text { Quilombola Pau } \\
\text { D’Arco para } \\
\text { compreender as } \\
\text { condições de saúde } \\
\text { básicas existentes nas } \\
\text { comunidades } \\
\text { quilombolas. }\end{array}$ & $\begin{array}{c}\text { Maiores de } 5 \text { anos, } \\
\text { sendo } 390 \\
\text { participantes }\end{array}$ & $\begin{array}{l}\text { Entamoeba coli }(57,5 \%), \\
\text { Endolimax nana }(56,4 \%) \mathrm{e} \\
\text { Giardia lamblia }(13,4 \%) .\end{array}$ & $45,9 \%$ & $\begin{array}{c}\text { Sedimentação } \\
\text { espontânea }\end{array}$ \\
\hline Pernambuco & $\begin{array}{l}\text { Cardozo, } \\
\text { Mendes, } \\
\text { França, } \\
\text { Simonetti \& } \\
\text { Cordeiro } \\
(2018)\end{array}$ & $\begin{array}{c}\text { Identificar a } \\
\text { incidência de } \\
\text { parasitoses intestinais } \\
\text { em uma população } \\
\text { assistida por um } \\
\text { hospital público do } \\
\text { agreste } \\
\text { pernambucano para } \\
\text { possibilitar a } \\
\text { aplicação de medidas } \\
\text { preventivas para } \\
\text { diminuição de } \\
\text { futuros casos de } \\
\text { contaminação }\end{array}$ & $\begin{array}{l}\text { Pacientes que } \\
\text { realizaram exames } \\
\text { parasitológicos de } \\
\text { fezes no período } \\
\text { de } 2015 \text { e } 2016 \text {, } \\
\text { sendo } 2.611 \\
\text { exames }\end{array}$ & $\begin{array}{c}\mathbf{2 0 1 5} \\
\text { Entamoeba coli }(36,8 \%), \\
\text { Giardia lamblia }(33,4 \%), \\
\text { Entamoeba histolytica } \\
(33,1 \%), \\
\text { Hymenolepis nana }(0,6 \%) \\
\mathbf{2 0 1 6} \\
\text { Endolimax nana }(46,0 \%), \\
\text { Giardia lamblia }(35,4 \%, \\
\text { Entamoeba histolytica } \\
\quad(34,4 \%), \\
\text { Hymenolepis nana }(0,3 \%),\end{array}$ & $\begin{array}{l}\text { 2015: } 37,9 \% \\
\text { 2016: } 40,7 \%\end{array}$ & $\begin{array}{l}\text { Método não } \\
\text { informado. }\end{array}$ \\
\hline
\end{tabular}


Research, Society and Development, v. 10, n. 8, e34810817497, 2021

(CC BY 4.0) | ISSN 2525-3409 | DOI: http://dx.doi.org/10.33448/rsd-v10i8.17497

\begin{tabular}{|c|c|c|c|c|c|c|}
\hline & & enteroparasitária. & & $\begin{array}{l}\text { Enterobius vermicularis } \\
\qquad(0,3 \%) .\end{array}$ & & \\
\hline Pernambuco & $\begin{array}{l}\text { Silva \& } \\
\text { Rocha } \\
(2019)\end{array}$ & $\begin{array}{c}\text { Realizar um } \\
\text { levantamento } \\
\text { parasitológico de } \\
\text { entero-helmintos a } \\
\text { partir dos dados do } \\
\text { Programa de } \\
\text { Controle de } \\
\text { Esquistossomose } \\
\text { (PCE) no município } \\
\text { do Xexéu-PE, no } \\
\text { período de } 2013 \text { a } \\
\text { 2015. }\end{array}$ & $\begin{array}{l}\text { Pessoas que } \\
\text { realizaram exame } \\
\text { parasitológico de } \\
\text { fezes no PCE, } \\
\text { sendo } 3.031 \text { laudos }\end{array}$ & $\begin{array}{c}\text { Schistosoma mansoni }(44,8 \%) \\
\text { Ascaris lumbricoides }(19,2 \%) \\
\text { Trichuristrichiura }(14,6 \%) \\
\text { Ancilostomídeos }(2,1 \%) \\
\text { Monoparasitoses }(80,9 \%), \\
\text { biparasitoses }(6,7 \%), \\
\text { poliparasitoses }(2,3 \%) .\end{array}$ & $15,7 \%$ & $\begin{array}{l}\text { Método não } \\
\text { informado. }\end{array}$ \\
\hline Maranhão & $\begin{array}{c}\text { Santos, } \\
\text { Campos \& } \\
\text { Firmo } \\
(2020)\end{array}$ & $\begin{array}{c}\text { Verificar a } \\
\text { ocorrência de } \\
\text { enteroparasitas em } \\
\text { pacientes atendidos } \\
\text { em um laboratório } \\
\text { público do município } \\
\text { de Alto Alegre do } \\
\text { Pindaré-MA. }\end{array}$ & $\begin{array}{c}\text { Exames de } \\
\text { parasitológicos de } \\
\text { fezes, sendo } 353 \\
\text { laudos }\end{array}$ & $\begin{array}{c}\text { Entamoeba coli }(72,0 \%), \\
\text { Entamoeba histolytica } \\
(22,0 \%), \\
\text { Giardia lamblia }(6,0 \%), \\
\text { Ascaris lumbricoides }(98,0 \%), \\
\text { Enterobius vermicularis }(2 \%) .\end{array}$ & $54,0 \%$ & $\begin{array}{l}\text { Método não } \\
\text { informado. }\end{array}$ \\
\hline Maranhão & $\begin{array}{l}\text { Oliveira } \text { et } \\
\text { al. }(2019)\end{array}$ & $\begin{array}{l}\text { Avaliar a presença de } \\
\text { enteroparasitoses em } \\
\text { alunos de escolas } \\
\text { públicas municipais. }\end{array}$ & $\begin{array}{l}40 \text { alunos em } 12 \\
\text { escolas municipais } \\
\text { de ensino } \\
\text { fundamental. }\end{array}$ & $\begin{array}{c}\text { Ancylostoma }(8,7 \%), \\
\text { Strongyloides }(8,7 \%), \\
\text { Hymenolepis }(4,3 \%), \\
\text { Ovos de Ascaris }(78,3 \%) .\end{array}$ & $55,0 \%$ & $\begin{array}{c}\text { Sedimentação } \\
\text { espontânea } \\
\text { por Hoffman } \\
\text { Pons \&Janer. }\end{array}$ \\
\hline Maranhão & $\begin{array}{l}\text { Silva, } \\
\text { Carvalho \& } \\
\text { Firmo } \\
(2016)\end{array}$ & $\begin{array}{c}\text { Comparar a } \\
\text { ocorrência de } \\
\text { parasitoses intestinais } \\
\text { em crianças de duas } \\
\text { comunidades da zona } \\
\text { rural, sendo uma a } \\
\text { mais próxima- Alto } \\
\text { dos Cearenses- e a } \\
\text { outra a mais distante- } \\
\text { Assentamento- da } \\
\text { zona urbana de Paulo } \\
\text { Ramos-MA. }\end{array}$ & $\begin{array}{l}42 \text { crianças de } 0 \text { a } \\
12 \text { anos, sendo } 21 \\
\text { da comunidade } \\
\text { Assentamento e } 21 \\
\text { do Alto dos } \\
\text { Cearenses. }\end{array}$ & $\begin{array}{c}\text { Assentamento: } \\
\text { Entamoeba coli (8 casos) } \\
\text { Ascaris lumbricoides }(4 \text { casos) } \\
\text { Ancilostomídeos }(2 \text { casos }) \\
\text { Entamoeba histolytica }(2) \\
\text { Endolimax nana }(2 \text { casos }) \\
\text { Monoparasitados }(50,0 \%) \\
\text { Biparasitados }(41,7 \%) \\
\text { Triparasitados }(8,3 \%) . \\
\text { Alto dos Cearenses: } \\
\text { Entamoeba coli }(2 \text { casos }) \\
\text { Endolimax nana }(1 \text { caso). } \\
\text { Monoparasitados }(66,7 \%), \\
\text { Biparasitados }(33,3 \%) \mathrm{e} \\
\text { nenhum triparasitado. }\end{array}$ & $\begin{array}{l}\text { Assentamento } \\
\text { com } 57,1 \% \\
\text { Alto dos } \\
\text { Cearenses } \\
\text { com } 14,3 \%\end{array}$ & $\begin{array}{c}\text { Sedimentação } \\
\text { espontânea } \\
\text { por Hofmann, } \\
\text { Pons e Janer } \\
\text { ou Lutz. }\end{array}$ \\
\hline Maranhão & $\begin{array}{l}\text { Sá-Silva, } \\
\text { Nunes, } \\
\text { Monroe, } \\
\text { Leite \& } \\
\text { Santos } \\
(2015)\end{array}$ & $\begin{array}{c}\text { Verificar a incidência } \\
\text { de enteroparasitos em } \\
\text { escolares do Ensino } \\
\text { Fundamental }\left(2^{\circ} \text { ao }\right. \\
\left.5^{\circ} \text { anos }\right) \text { de duas } \\
\text { escolas da rede } \\
\text { pública municipal de } \\
\text { São Luís, Maranhão. }\end{array}$ & $\begin{array}{l}230 \text { alunos na } \\
\text { primeira escola e } \\
126 \text { alunos na } \\
\text { segunda escola }\end{array}$ & $\begin{array}{c}\text { PRIMEIRA ESCOLA: } \\
\text { Ascaris lumbricoides }(34,2 \%), \\
\text { Ancilostomídeos }(17,8 \%), \\
\text { Trichuris trichiura }(12,3 \%), \\
\text { Enterobius vermicularis } \\
\text { (9,5\%), } \\
\text { Entamoeba coli }(52,0 \%), \\
\text { Iodamoeba butschilli }(38,3 \%), \\
\text { Giardia lamblia }(9,5 \%) \\
\text { Monoparasitadas }(72,2 \%), \\
\text { biparasitadas }(21,9 \%), \\
\text { triparasitadas }(6,8 \%) . \\
\text { SEGUNDA ESCOLA: } \\
\text { Ascaris lumbricoides }(50,0 \%), \\
\text { Enterobius vermicularis } \\
\text { (20,0\%), } \\
\text { Trichuris trichiura }(20,0 \%), \\
\text { Ancilostomídeos }(10,0 \%), \\
\text { Entamoeba coli }(63,8 \%),\end{array}$ & $\begin{array}{l}31,7 \%, \text { na } \\
\text { primeira } \\
\text { escola } 32,5 \%, \\
\text { na segunda } \\
\text { escola. }\end{array}$ & $\begin{array}{l}\text { Método de } \\
\text { Hofmam, } \\
\text { Pons e Janer } \\
\text { ou Método de } \\
\text { Sedimentação } \\
\text { Espontânea. }\end{array}$ \\
\hline
\end{tabular}


Research, Society and Development, v. 10, n. 8, e34810817497, 2021

(CC BY 4.0) | ISSN 2525-3409 | DOI: http://dx.doi.org/10.33448/rsd-v10i8.17497

\begin{tabular}{|c|c|c|c|c|c|c|}
\hline & & & & $\begin{array}{c}\text { Iodamoeba butschilli }(33,3 \%), \\
\text { Entamoeba histolytica }(2,7 \%), \\
\text { Monoparasitadas }(12,1 \%), \\
\text { biparasitadas }(87,9 \%) .\end{array}$ & & \\
\hline Maranhão & $\begin{array}{l}\text { Melo, } \\
\text { Ericeira, } \\
\text { Oliveira, } \\
\text { Rocha \& } \\
\text { Firmo } \\
(2015)\end{array}$ & $\begin{array}{l}\text { Identificar a presença } \\
\text { de parasitos } \\
\text { intestinais em laudos } \\
\text { parasitológicos de } \\
\text { fezes de pacientes } \\
\text { atendidos em um } \\
\text { laboratório privado } \\
\text { do município de } \\
\text { Bacabal-MA. }\end{array}$ & $\begin{array}{l}723 \text { resultados } \\
\text { coprológicos }\end{array}$ & $\begin{array}{c}\text { Entamoeba coli }(50,8 \%), \\
\text { Endolimax nana }(24,0 \%), \\
\text { Entamoeba histolytica } \\
(15,5 \%), \\
\text { Giardia lamblia }(9,7 \%), \\
\text { Ascaris lumbricoides }(78,3 \%), \\
\text { Ancilostomídeos }(17,4 \%), \\
\text { Trichuris trichiura }(4,3 \%) \\
\text { poliparasitoses }(32,5 \%) .\end{array}$ & $27,2 \%$ & $\begin{array}{l}\text { Método não } \\
\text { informado. }\end{array}$ \\
\hline Maranhão & $\begin{array}{l}\text { Sousa et al. } \\
\quad(2019)\end{array}$ & $\begin{array}{c}\text { Determinar a } \\
\text { prevalência de } \\
\text { parasitoses intestinais } \\
\text { em crianças } \\
\text { frequentadoras de } \\
\text { uma escola pública } \\
\text { municipal. }\end{array}$ & $\begin{array}{c}50 \text { alunos, entre } 6 \\
\text { a } 12 \text { anos }\end{array}$ & $\begin{array}{c}\text { Entamoeba coli }(38,0 \%), \\
\text { Ascaris lumbricoides }(31,0 \%), \\
\text { Endolimax nana }(27,0 \%), \\
\text { Giardia lamblia }(12,0 \%), \\
\text { monoparasitados }(81,0 \%), \\
\text { biparasitados }(19,0 \%) .\end{array}$ & $52,0 \%$ & $\begin{array}{l}\text { Métodos de } \\
\text { Hoffman, } \\
\text { Pons e Janer } \\
\text { e método de } \\
\text { Willis. } \\
\text { Para } \\
\text { protozoários, } \\
\text { foi feita } \\
\text { através do } \\
\text { método de } \\
\text { Faust. }\end{array}$ \\
\hline Maranhão & $\begin{array}{l}\text { Gomes } \boldsymbol{e t} \\
\text { al. }(2016)\end{array}$ & $\begin{array}{l}\text { Levar conhecimento } \\
\text { a comunidades } \\
\text { periféricas, utilizando } \\
\text { como estratégia a } \\
\text { Educação em Saúde, } \\
\text { a respeito das } \\
\text { parasitoses intestinais } \\
\text { e seus efeitos na } \\
\text { população humana, } \\
\text { enfatizando as ações } \\
\text { de higiene pessoal e } \\
\text { saneamento básico } \\
\text { como fatores de } \\
\text { prevenção para tais } \\
\text { doenças. }\end{array}$ & $\begin{array}{l}143 \text { crianças, de } 2 \\
\text { a } 10 \text { anos, em três } \\
\text { comunidades do } \\
\text { município de } \\
\text { Grajaú - MA. }\end{array}$ & $\begin{array}{c}\text { Ascaris lumbricoides }(13,9 \%), \\
\text { Entamoeba coli }(33,7 \%), \\
\text { Entamoeba histolytica }(4,6 \%), \\
\text { Iodamoeba bustshlii }(9,3 \%), \\
\text { Giardia lamblia }(20,9 \%), \\
\text { G. intestinalis }(1,1 \%), \\
\text { Endolimax nana }(16,2 \%) \\
\text { Biparasitadas }(13,9 \%) .\end{array}$ & $60,1 \%$ & $\begin{array}{l}\text { Método de } \\
\text { Hoffman, } \\
\text { Faust e } \\
\text { Ritchi. }\end{array}$ \\
\hline Maranhão & $\begin{array}{l}\text { Rodrigues, } \\
\text { Gomes, } \\
\text { Lima \& } \\
\text { Nascimento } \\
\text { (2018) }\end{array}$ & $\begin{array}{c}\text { Investigar a } \\
\text { prevalência e os } \\
\text { fatores associados à } \\
\text { ocorrência de } \\
\text { parasitismo intestinal } \\
\text { em crianças da zona } \\
\text { urbana do município } \\
\text { de Grajaú, Maranhão. }\end{array}$ & $\begin{array}{l}143 \text { crianças de } 2 \text { a } \\
10 \text { anos de idade } \\
\text { de três } \\
\text { comunidades do } \\
\text { município de } \\
\text { Grajaú - MA. }\end{array}$ & $\begin{array}{c}\text { Ascaris lumbricoides }(13,9 \%), \\
\text { Entamoeba coli }(33,7 \%), \\
\text { Entamoeba histolytica }(4,6 \%), \\
\text { Iodamoeba bustshlii }(9,3 \%), \\
\text { Giardia lamblia }(20,9 \%), \\
\text { Giardia intestinalis }(1,1 \%), \\
\text { Endolimax nana }(16,2 \%) .\end{array}$ & $60,1 \%$ & $\begin{array}{l}\text { Método de } \\
\text { Hoffman, } \\
\text { Faust e } \\
\text { Ritchi. }\end{array}$ \\
\hline Ceará & $\begin{array}{l}\text { Maia, } \\
\text { Hassum \& } \\
\text { Valladares } \\
\text { (2015) }\end{array}$ & $\begin{array}{c}\text { Apresentar a } \\
\text { frequência parasitária } \\
\text { em usuários do } \\
\text { Sistema Único de } \\
\text { Saúde (SUS), em } \\
\text { Limoeiro do Norte- } \\
\text { CE. }\end{array}$ & $\begin{array}{l}1.266 \text { laudos de } \\
\text { exames de } 13 \\
\text { Unidades Básicas } \\
\text { de Saúde (UBS's) } \\
\text { municipais e áreas } \\
\text { descobertas. }\end{array}$ & $\begin{array}{c}\text { FREQUÊNCIA } \\
\text { Endolimax nana }(44,2 \%), \\
\text { Entamoeba coli }(27,4 \%), \\
\text { Giardia lamblia }(16,3 \%), \\
\text { Iodamoeba sp. }(6,2 \%), \\
\text { Entamoeba histolystica/dispar } \\
(4,4 \%), \text { Enterobius } \\
\text { vermiculares }(0,7 \%), \\
\text { Ancylostoma sp. }(0,5 \%), \\
\text { Ascaris lumbricoides }(0,2 \%), \\
\text { monoparasitadas }(75,9 \%), \\
\text { biparasitadas }(18,0 \%), \\
\text { poliparasitadas }(6,1 \%) .\end{array}$ & $23,3 \%$ & $\begin{array}{c}\text { Sedimentação } \\
\text { espontânea. }\end{array}$ \\
\hline Ceará & $\begin{array}{l}\text { Lima, Maia, } \\
\text { Hassum, } \\
\text { Valladares } \\
\& \text { Freitas } \\
\text { (2015) }\end{array}$ & $\begin{array}{l}\text { Verificar se há } \\
\text { correlação entre o } \\
\text { atendimento } \\
\text { domiciliar por } \\
\text { Sistema de } \\
\text { Abastecimento de } \\
\text { Água (SAA) e }\end{array}$ & $\begin{array}{l}2.704 \text { exames de } \\
\text { crianças de } 0 \text { a } 9 \\
\text { anos, adolescentes } \\
\text { de } 10 \text { a } 19 \text { anos, } \\
\text { adultos de } 20 \text { a } 59 \\
\text { anos, e idosos } \\
\text { acima de } 60 \text { anos. }\end{array}$ & $\begin{array}{c}\text { FREQUÊNCIA } \\
\text { Ascaris lumbricoides }(<1 \%), \\
\text { Ancylostoma sp. }(<1 \%), \\
\text { Enterobius vermiculares } \\
(0,7 \%), \text { Hymenolepis nana }(< \\
1 \%), \text { Hymenolepis diminuta }(< \\
1 \%), \text { Entamoeba }\end{array}$ & $\begin{array}{l}24,9 \%(2010) \\
20,1 \%(2011) \\
17,7 \%(2012) \\
16,9 \%(2013)\end{array}$ & $\begin{array}{c}\text { Sedimentação } \\
\text { espontânea. }\end{array}$ \\
\hline
\end{tabular}


Research, Society and Development, v. 10, n. 8, e34810817497, 2021

(CC BY 4.0) | ISSN 2525-3409 | DOI: http://dx.doi.org/10.33448/rsd-v10i8.17497

\begin{tabular}{|c|c|c|c|c|c|c|}
\hline & & $\begin{array}{c}\text { Serviço de } \\
\text { Esgotamento } \\
\text { Sanitário (SES) no } \\
\text { município de } \\
\text { Limoeiro do Norte } \\
\text { entre } 2010 \text { a 2013, de } \\
\text { acordo com o } \\
\text { Sistema Nacional de } \\
\text { Informações do } \\
\text { Saneamento (SNIS), } \\
\text { e a prevalência } \\
\text { enteroparasitária em } \\
\text { usuários do Sistema } \\
\text { Único de Saúde do } \\
\text { referido município. }\end{array}$ & & $\begin{array}{c}\text { histolysticaldispar }(3,3 \%), \\
\text { Entamoeba coli }(24,1 \%), \\
\text { Endolimax nana }(38,1 \%), \\
\text { Iodamoeba sp. }(5,2 \%), \\
\text { Giardia lamblia }(25,0 \%), \\
\text { Balantidium coli }(<1 \%) .\end{array}$ & & \\
\hline Ceará & $\begin{array}{l}\text { Asevedo, } \\
\text { Andrade, } \\
\text { Alves \& } \\
\text { Barbosa } \\
(2017)\end{array}$ & $\begin{array}{l}\text { Descrever a } \\
\text { prevalência de } \\
\text { infectados e as } \\
\text { espécies de parasitos } \\
\text { encontradas na } \\
\text { população alvo. }\end{array}$ & 7 a 17 anos & $\begin{array}{c}\text { E. histolytica/E.dispar } \\
(45,7 \%), \text { G. lamblia }(20,0 \%), \\
\text { E. coli }(11,4 \%)\end{array}$ & $25,9 \%$ & $\begin{array}{c}\text { Sedimentação } \\
\text { espontânea. }\end{array}$ \\
\hline Ceará & $\begin{array}{l}\text { Santos, } \\
\text { Nascimento, } \\
\text { Cristo \& } \\
\text { Vandesmet } \\
\text { (2016) }\end{array}$ & $\begin{array}{l}\text { Verificar a } \\
\text { ocorrência de anemia } \\
\text { associada às } \\
\text { parasitoses intestinais } \\
\text { em pacientes } \\
\text { atendidos em um } \\
\text { Laboratório de } \\
\text { Análises Clinicas no } \\
\text { município de } \\
\text { Juazeiro do } \\
\text { Norte/CE. }\end{array}$ & $\begin{array}{c}72 \text { prontuários de } \\
\text { usuários do } \\
\text { Laboratório de } \\
\text { Análises Clínicas } \\
\text { entre } 0 \text { e } 63 \text { anos. }\end{array}$ & $\begin{array}{c}\text { Giardia lamblia }(50,0 \%), \\
\text { Endolimax nana }(36,0 \%), \\
\text { Entamoeba Coli }(7,0 \%), \\
\text { Balantidium Coli }(7,0 \%) .\end{array}$ & $\begin{array}{c}50,0 \%(0 \text { a } 13 \\
\text { anos) } \\
42,8 \%(14 \text { a } \\
49 \text { anos }) \\
7,2 \%(>50 \\
\text { anos) }\end{array}$ & $\begin{array}{c}\text { Sedimentação } \\
\text { espontânea e } \\
\text { centrífuga- } \\
\text { flutuação. }\end{array}$ \\
\hline Ceará & $\begin{array}{l}\text { Maia, } \\
\text { Valladares } \\
\text { \& Hassum } \\
\text { (2016) }\end{array}$ & $\begin{array}{c}\text { Especializar a } \\
\text { prevalência de } \\
\text { enteroparasitoses nos } \\
\text { territórios adstritos } \\
\text { das Unidades Básicas } \\
\text { de Saúde (UBSs) de } \\
\text { Limoeiro do Norte, } \\
\text { Ceará, Brasil. }\end{array}$ & $\begin{array}{l}3.824 \text { exames } \\
\text { parasitológicosde } \\
\text { usuários das } \\
\text { UBS's com idade } \\
\text { entre } 0 \text { e } 9 \text { anos; } \\
\text { entre } 10 \text { e } 19 ; \\
\text { entre } 20 \text { e } 59 ; \text { e } \\
\text { com idade acima } \\
\text { de } 60 \text { anos. }\end{array}$ & $\begin{array}{l}\text { Endolimax nana }(42,1 \%), \\
\text { Entamoeba coli }(25,5 \%), \\
\text { Giardia lamblia }(21,2 \%) .\end{array}$ & $19,6 \%$ & $\begin{array}{c}\text { Sedimentação } \\
\text { espontânea. }\end{array}$ \\
\hline Ceará & $\begin{array}{l}\text { Almeida, } \\
\text { Souza, } \\
\text { Mourão \& } \\
\text { Pantoja } \\
\text { (2017) }\end{array}$ & $\begin{array}{l}\text { Analisar prevalência } \\
\text { de enteroparasitas } \\
\text { em amostras fecais } \\
\text { provenientes de } \\
\text { pacientes da rede } \\
\text { pública e privada da } \\
\text { Região Metropolitana } \\
\text { de Fortaleza - CE. }\end{array}$ & $\begin{array}{c}6.596 \text { participantes } \\
\text { de diversas faixas } \\
\text { etárias. }\end{array}$ & $\begin{array}{c}\text { Endolimax nana }(55,1 \%), \\
\text { Entamoeba coli }(21,3 \%), \\
\text { Giardia lamblia }(13,9 \%), \\
\text { Ascaris lumbricoides }(1,3 \%), \\
\text { Trichocephalus trichiurus } \\
\text { (0,6\%), Enterobius } \\
\text { vermiculares }(0,3 \%), \\
\text { Hymenolepis nana }(0,6 \%), \\
\text { Fasciola hepatica }(0,1 \%), \\
\text { Taenia sp. }(0,1 \%) .\end{array}$ & $12,7 \%$ & $\begin{array}{l}\text { Método de } \\
\text { Blagg, } \\
\text { Sedimentação } \\
\text { espontânea e } \\
\text { Hematoxilina } \\
\text { férrica de } \\
\text { Heidenhai. }\end{array}$ \\
\hline Ceará & $\begin{array}{l}\text { Pereira } \boldsymbol{e t} \\
\boldsymbol{a l} .(2018)\end{array}$ & $\begin{array}{l}\text { Determinar a } \\
\text { prevalência das } \\
\text { parasitoses intestinais } \\
\text { em crianças } \\
\text { residentes em áreas } \\
\text { desprovidas de } \\
\text { infraestrutura } \\
\text { ambiental, do } \\
\text { município de } \\
\text { Juazeiro do Norte - } \\
\text { Ceará. }\end{array}$ & $\begin{array}{l}\text { Crianças de } 1 \text { a } 6 \\
\text { anos, sendo } 96 \\
\text { participantes }\end{array}$ & $\begin{array}{c}\text { Entamoeba histolytica } \\
(53,5 \%), \text { Entamoeba coli } \\
(17,6 \%), \text { Endolimax nana } \\
(11,7 \%), \text { Giardia lamblia } \\
(10,3 \%), \text { Enterobius } \\
\text { vermicularis }(5,3 \%), \text { Ascaris } \\
\text { lumbricoides }(5,3 \%), \\
\text { Hymenolepis nana }(5,3 \%), \\
\text { Ancylostoma sp. }(5,3 \%) \\
\text { Monoparasitados }(73,7 \%), \\
\text { poliparasitados }(26,3 \%) .\end{array}$ & $40,0 \%$ & $\begin{array}{c}\text { Sedimentação } \\
\text { espontânea. }\end{array}$ \\
\hline
\end{tabular}


Research, Society and Development, v. 10, n. 8, e34810817497, 2021

(CC BY 4.0) | ISSN 2525-3409 | DOI: http://dx.doi.org/10.33448/rsd-v10i8.17497

\begin{tabular}{|c|c|c|c|c|c|c|}
\hline Alagoas & $\begin{array}{l}\text { Silva, Silva } \\
\text { \& Rocha } \\
\text { (2018) }\end{array}$ & $\begin{array}{c}\text { Descrever o perfil } \\
\text { epidemiológico } \\
\text { das enteroparasitoses } \\
\text { pela população } \\
\text { atendida no } \\
\text { laboratório de } \\
\text { análises clínicas } \\
\text { privado. }\end{array}$ & $\begin{array}{l}\text { 14.301 laudos de } \\
\text { exames de um } \\
\text { laboratório, de } \\
\text { todas as faixas } \\
\text { etárias }\end{array}$ & $\begin{array}{c}\text { Endolimax nana } \\
(43,1 \%), \text { Giardia lamblia } \\
(18,9 \%), \text { Entamoeba histolyt } \\
\text { icaldíspar }(17,9 \%), \\
\text { Entamoeba coli }(15,5 \%), \\
\text { Iodamoeba butshlii }(2,8 \%), \\
\text { Ancylostomatidae }(0.5 \%), \\
\text { Ascaris lumbricoides }(0,3 \%), \\
\text { Strongyloides stercoralis } \\
(0,3 \%), \text { Schistosoma mansoni } \\
(0,2 \%), \text { Hymenolepis nana } \\
(0,2 \%) \text { e Enterobius } \\
\text { vermicularis } \\
(0,1 \%)\end{array}$ & $6,0 \%$ & $\begin{array}{l}\text { Sedimentação } \\
\text { espontânea. }\end{array}$ \\
\hline Paraíba & $\begin{array}{l}\text { Pedraza } \\
(2016)\end{array}$ & $\begin{array}{l}\text { Caracterizar o perfil } \\
\text { nutricional e de } \\
\text { morbidade das } \\
\text { crianças assistidas } \\
\text { em creches públicas } \\
\text { do município de } \\
\text { Campina Grande, na } \\
\text { Paraíba. }\end{array}$ & $\begin{array}{c}299 \text { crianças a } \\
\text { partir de } 9 \text { meses }\end{array}$ & $\begin{array}{c}\text { Ascaris lumbricoides }(16,5 \%), \\
\text { Trichuris trichiura }(0,8 \%), \\
\text { Enterobius vermicularis } \\
(0,8 \%), \text { Entamoeba coli } \\
(44,4 \%), \text { Entamoeba } \\
\text { histolytica }(42,7 \%), \\
\text { Iodamoeba butschlii }(0,4 \%), \\
\text { Endolimax nana }(11,3 \%), \\
\text { Giardia lamblia }(38,3 \%), \\
\text { Protozoários }(79,8 \%), \\
\text { Helmintos }(16,9 \%), \\
\text { Poliparasitose }(46,4 \%) .\end{array}$ & $82,7 \%$ & $\begin{array}{l}\text { Hoffman, } \\
\text { Pons e Janer. }\end{array}$ \\
\hline Paraíba & $\begin{array}{c}\text { Silva, } \\
\text { Andrade, } \\
\text { Cavalcante, } \\
\text { Lima \& } \\
\text { Freitas } \\
\text { (2018) }\end{array}$ & $\begin{array}{c}\text { Pesquisar } \\
\text { enteroparasitos } \\
\text { crianças de creches, } \\
\text { verificar a ocorrência } \\
\text { de estruturas como } \\
\text { ovos e larvas de } \\
\text { helmintos em } \\
\text { elementos sanitários } \\
\text { e promover medidas } \\
\text { educativas de higiene } \\
\text { e prevenção em } \\
\text { creches do município } \\
\text { de João Pessoa. }\end{array}$ & $\begin{array}{c}67 \text { crianças de } 2 \\
\text { creches com } \\
\text { idades entre } 1 \text { e } 12 \\
\text { anos }\end{array}$ & $\begin{array}{c}\text { Ascaris lumbricoides }(16,1 \%), \\
\text { Trichuris trichiura }(6,4 \%), \\
\text { Ancylostomatidae }(1,6 \%), \\
\text { Enterobius vermicularis } \\
(1,6 \%), \\
\text { Giardia lamblia }(17,7 \%), \\
\text { Endolimax nana }(33,9 \%), \\
\text { Entamoeba histolytica/dispar } \\
(3,2 \%), \\
\text { Entamoeba coli }(17,7 \%), \\
\text { Iodamoeba butschlii }(1,6 \%) \\
\text { Monoparasitados }(46,0 \%), \\
\text { biparasitados }(43,0 \%), \\
\text { poliparasitados }(11,0 \%) .\end{array}$ & $55,2 \%$ & $\begin{array}{l}\text { Sedimentação } \\
\text { espontânea. }\end{array}$ \\
\hline Paraíba & $\begin{array}{l}\text { Dias et al. } \\
\text { (2017) }\end{array}$ & $\begin{array}{c}\text { Realizar um estudo } \\
\text { coproparasitológico e } \\
\text { epidemiológico em } \\
\text { crianças e } \\
\text { manipuladores de } \\
\text { alimentos em uma } \\
\text { creche de uma cidade } \\
\text { da Paraíba, } \\
\text { avaliando-se os } \\
\text { dados coletados do } \\
\text { período de } 2013 \text { a } \\
2015 .\end{array}$ & $\begin{array}{c}\text { 2013: } 53 \text { crianças } \\
\text { 2014: } 67 \text { crianças } \\
\text { 2015: } 44 \text { crianças } \\
114 \\
\text { manipuladores, } \\
\text { cuidadores e pais } \\
\text { ou responsáveis } \\
\text { pelas crianças, } \\
\text { com idades entre } 1 \\
\text { e } 50 \text { anos }\end{array}$ & $\begin{array}{c}\text { Ascaris lumbricoides }(56,1 \%), \\
\text { Ancylostomatidae }(5,3 \%), \\
\text { Trichuris trichiura }(36,8 \%), \\
\text { Schistossoma mansoni } \\
(1,8 \%), \\
\text { Giardia duodenalis }(32,9 \%), \\
\text { Endolimax nana }(35,4 \%), \\
\text { Entamoeba histolytica } \\
(15,9 \%), \\
\text { Entamoeba coli }(15,2 \%), \\
\text { Iodamoeba butschllii } \\
(0,6 \%) .\end{array}$ & $55,7 \%$ & $\begin{array}{l}\text { Sedimentação } \\
\text { espontânea. }\end{array}$ \\
\hline Paraíba & $\begin{array}{l}\text { Lins et al. } \\
\text { (2016) }\end{array}$ & $\begin{array}{c}\text { Identificar a presença } \\
\text { de enteroparasitos em } \\
\text { crianças atendidas } \\
\text { em uma creche no } \\
\text { distrito de Galante, } \\
\text { município de } \\
\text { Campina Grande, no } \\
\text { período de maio a } \\
\text { agosto de } 2016, \\
\text { especificamente } \\
\text { utilizando dois } \\
\text { métodos para o } \\
\text { diagnóstico do }\end{array}$ & $\begin{array}{l}44 \text { crianças com } \\
\text { idade entre } 2 \text { e } 5 \\
\text { anos de idade. }\end{array}$ & $\begin{array}{c}\text { Enterobius vermicularis: } 1 \\
\text { caso pelo método de Graham e } \\
1 \text { caso pelo método de } \\
\text { Hoffman, Pons e Janer. }\end{array}$ & $4,5 \%$ & $\begin{array}{l}\text { Para a } \\
\text { pesquisa de } \\
\text { ovos na } \\
\text { região } \\
\text { perianal, } \\
\text { conhecido } \\
\text { como método } \\
\text { de Graham e } \\
\text { outro para } \\
\text { pesquisa de } \\
\text { ovos nas } \\
\text { fezes, o } \\
\text { método de }\end{array}$ \\
\hline
\end{tabular}


Research, Society and Development, v. 10, n. 8, e34810817497, 2021

(CC BY 4.0) | ISSN 2525-3409 | DOI: http://dx.doi.org/10.33448/rsd-v10i8.17497

\begin{tabular}{|c|c|c|c|c|c|c|}
\hline & & $\begin{array}{c}\text { Enterobius } \\
\text { vermicularis: um } \\
\text { método específico } \\
\text { para pesquisa de ovos } \\
\text { na região perianal } \\
\text { (Graham) e outro } \\
\text { para pesquisa de ovos } \\
\text { nas fezes } \\
\text { (Sedimentação } \\
\text { espontânea em água). }\end{array}$ & & & & $\begin{array}{l}\text { Hoffmam, } \\
\text { Pons e Janer. }\end{array}$ \\
\hline Paraíba & $\begin{array}{l}\text { Gonçalves, } \\
\text { Fernandes, } \\
\text { Medeiros \& } \\
\text { Oliveira } \\
\text { (2016) }\end{array}$ & $\begin{array}{c}\text { Promover a } \\
\text { identificação do } \\
\text { perfil } \\
\text { enteroparasitológico } \\
\text { dos pacientes } \\
\text { atendidos pelo } \\
\text { laboratório de } \\
\text { análises clínicas da } \\
\text { policlínica de } \\
\text { Cajazeiras-PB. }\end{array}$ & $\begin{array}{l}514 \text { amostras de } \\
\text { fezes de todas as } \\
\text { faixas etárias. }\end{array}$ & $\begin{array}{c}\text { FREQUÊNCIA } \\
\text { Enterobius vermicularis }(1 \\
\text { caso), } \\
\text { Entamoeba histolytica } \\
(56,0 \%), \\
\text { Entamoeba coli }(22,0 \%), \\
\text { Giardia lamblia }(16,0 \%), \\
\text { Endolimax nana }(6,0 \%), \\
\text { monoparasitismo }(86,0 \%), \\
\text { multiparasitismo }(14,0 \%) .\end{array}$ & $30,0 \%$ & $\begin{array}{l}\text { Hoffman, } \\
\text { Pons e Janer. }\end{array}$ \\
\hline Paraíba & $\begin{array}{l}\text { Sales, } \\
\text { Queiroga, } \\
\text { Olinda \& } \\
\text { Pedraza } \\
(2015)\end{array}$ & $\begin{array}{c}\text { Analisar a } \\
\text { associação entre } \\
\text { infecções } \\
\text { enteroparasitárias e } \\
\text { características de } \\
\text { creches públicas } \\
\text { frequentadas por } \\
\text { crianças pré- } \\
\text { escolares do } \\
\text { município de } \\
\text { Campina Grande, } \\
\text { Paraíba, Brasil. }\end{array}$ & $\begin{array}{c}248 \text { crianças } \\
\text { institucionalizadas, } \\
\text { na } \\
\text { faixa etária dos } 6 \\
\text { - } 72 \text { meses. }\end{array}$ & $\begin{array}{c}\text { crianças com idade superior } \\
\text { a } 25 \text { meses } \\
\text { A. lumbricoides }(15,7 \%), E . \\
\text { coli }(60,4 \%), \text {. histolytica } \\
(40,7 \%), \text { poliparasitoses } \\
(44,3 \%) . \\
\text { crianças com idade menor ou } \\
\text { igual a } 24 \text { meses } \\
\text { A. lumbricoides }(0,8 \%), E \text {. coli } \\
(2,0 \%), \text { E. histolytica }(2,0 \%), \\
\text { poliparasitoses }(2,0 \%) .\end{array}$ & $\begin{array}{c}\text { Não } \\
\text { informado. }\end{array}$ & $\begin{array}{l}\text { Hoffman, } \\
\text { Pons e Janer. }\end{array}$ \\
\hline Paraíba & $\begin{array}{l}\text { Oliveira e } \\
\text { Barbosa } \\
(2019)\end{array}$ & $\begin{array}{l}\text { Fazer o diagnóstico } \\
\text { coproparasitoscópico, } \\
\text { conhecer o perfil } \\
\text { epidemiológico e } \\
\text { analisar as variáveis } \\
\text { envolvidas na } \\
\text { infecção de } \\
\text { indivíduos da cidade } \\
\text { de Araruna-PB. }\end{array}$ & $\begin{array}{l}100 \text { amostras } \\
\text { fecais de todas as } \\
\text { faixas etárias }\end{array}$ & $\begin{array}{l}\text { Entamoeba coli }(31,4 \%), \\
\text { Endolimax nana }(20,0 \%), \\
\text { Ascaris lumbricoides }(8,6 \%), \\
\text { E. dispar/E. histolytica }(5,7 \%), \\
\text { Giardia lamblia }(2,9 \%) .\end{array}$ & $35,0 \%$ & $\begin{array}{l}\text { Hoffman, } \\
\text { Pons e Janer } \\
\text { coradas com } \\
\text { solução de } \\
\text { Lugol. }\end{array}$ \\
\hline Paraíba & $\begin{array}{l}\text { Soares et al. } \\
\quad(2016)\end{array}$ & $\begin{array}{c}\text { Realizar um } \\
\text { rastreamento } \\
\text { coproparasitológico } \\
\text { em crianças de uma } \\
\text { creche pública na } \\
\text { cidade de Campina } \\
\text { Grande-PB, a fim de } \\
\text { identificar a presença } \\
\text { de possíveis } \\
\text { enteroparasitas nestes } \\
\text { indivíduos. }\end{array}$ & $\begin{array}{c}44 \text { crianças de } 2 \text { a } \\
5 \text { anos }\end{array}$ & $\begin{array}{c}\text { Giardia lamblia } \\
(25,0 \%), \text { Endolimax nana } \\
(15,9 \%) \mathrm{e} \\
\text { Entamoeba coli } \\
(13,6 \%) . \\
\text { Enterobius vermicularis } \\
(4,5 \%) \mathrm{e} \\
\text { Ascaris lumbricoides } \\
(2,3 \%) . \text { Poliparasitados } \\
(17,4 \%) .\end{array}$ & $52,3 \%$ & $\begin{array}{l}\text { Métodos de } \\
\text { Hoffman, } \\
\text { Pons e Janer; } \\
\text { Graham } \\
\text { modificado, } \\
\text { Kato-Katz e } \\
\text { Rugai, } \\
\text { Mattos e } \\
\text { Brisola. }\end{array}$ \\
\hline Piauí & $\begin{array}{l}\text { Cardoso et } \\
\text { al. }(2020)\end{array}$ & $\begin{array}{l}\text { Analisar amostras } \\
\text { fecais e descrever o } \\
\text { perfil epidemiológico } \\
\text { e socioeconômico de } \\
\text { crianças de } 03 \text { a } 10 \\
\text { anos de idade em três } \\
\text { comunidades } \\
\text { carentes em } \\
\text { Teresina-PI. }\end{array}$ & $\begin{array}{l}130 \text { crianças, de } 3 \\
\text { a } 10 \text { anos de idade }\end{array}$ & $\begin{array}{c}\text { Endolimax nana }(64,0 \%), \\
\text { Entamoeba coli }(26,0 \%), \\
\text { Giardia sp. }(22,0 \%), \\
\text { Entamoeba histolytica/dispar } \\
(22,0 \%), \\
\text { Blastocystis hominis }(4,0 \%), \\
\text { Iodamoeba butschlii }(6,0 \%) .\end{array}$ & $39,2 \%$ & $\begin{array}{c}\text { Ritchie } \\
\text { modificado } \\
(1948), \\
\text { Willis- } \\
\text { Mollay } \\
\text { modificado } \\
\text { (1921). }\end{array}$ \\
\hline Piauí & $\begin{array}{l}\text { Leite, Neto, } \\
\text { Sátiro, } \\
\text { Fonseca e } \\
\text { Ventura } \\
(2018)\end{array}$ & $\begin{array}{c}\text { Determinar a } \\
\text { ocorrência de } \\
\text { enteroparasitoses em } \\
\text { crianças atendidas } \\
\text { em um laboratório do } \\
\text { município de }\end{array}$ & $\begin{array}{c}1.406 \text { crianças }(0- \\
12 \text { anos), entre os } \\
\text { anos de } 2013- \\
2018 .\end{array}$ & $\begin{array}{c}\text { Endolimax nana }(59,0 \%), \\
\text { Entamoeba coli }(15,7 \%), \\
\text { Iodamoeba butschllii } \\
(0,4 \%), \\
\text { Giardia duodenalis }(6,6 \%),\end{array}$ & $31,0 \%$ & $\begin{array}{l}\text { Hoffman, } \\
\text { Pons e Janer. }\end{array}$ \\
\hline
\end{tabular}


Research, Society and Development, v. 10, n. 8, e34810817497, 2021

(CC BY 4.0) | ISSN 2525-3409 | DOI: http://dx.doi.org/10.33448/rsd-v10i8.17497

\begin{tabular}{|c|c|c|c|c|c|c|}
\hline & & $\begin{array}{l}\text { Parnaíba-PI, assim } \\
\text { como correlacionar } \\
\text { com as estações } \\
\text { climáticas, seca e } \\
\text { chuvosa. }\end{array}$ & & $\begin{array}{c}\text { Ascaris lumbricoides }(0,2 \%), \\
\text { Trichuris trichiura }(0,4 \%), \\
\text { Enterobius vermicularis } \\
(0,9 \%), \\
\text { Himenolepis nana }(0,2 \%), \\
\text { Trichostrongylus sp. }(0,2 \%), \\
\text { Biparasitismo }(14,6 \%), \\
\text { Poliparasitismo }(1,3 \%)\end{array}$ & & \\
\hline Piauí & $\begin{array}{l}\text { Sampaio e } \\
\text { Barros } \\
\text { (2017) }\end{array}$ & $\begin{array}{c}\text { Determinar a } \\
\text { prevalência das } \\
\text { enteroparasitoses que } \\
\text { acometem a } \\
\text { população do } \\
\text { município de } \\
\text { Beneditinos, interior } \\
\text { do Estado do Piauí- } \\
\text { Brasil. }\end{array}$ & $\begin{array}{l}116 \text { laudos e todas } \\
\text { as faixas etárias }\end{array}$ & $\begin{array}{c}\text { Entamoeba coli }(21,5 \%), \\
\text { E. histolytica/dispar }(21,5 \%), \\
\text { Endolimax nana }(21,5 \%), \\
\text { Giardia lamblia }(7,1 \%), \\
\text { Strongyloides stercoralis } \\
(7,1 \%) \\
\text { Biparasitados }(21,3 \%) .\end{array}$ & $12,2 \%$ & $\begin{array}{l}\text { Hoffman, } \\
\text { Pons e Janer. }\end{array}$ \\
\hline Piauí & $\begin{array}{l}\text { Ramos et al. } \\
\text { (2019) }\end{array}$ & $\begin{array}{l}\text { Avaliar os hábitos de } \\
\text { frequência do } \\
\text { consumo } \\
\text { alimentar, estado } \\
\text { nutricional e a } \\
\text { ocorrência de } \\
\text { enteroparasitos } \\
\text { em crianças pré- } \\
\text { escolares de } 3 \text { a } 6 \\
\text { anos de uma escola } \\
\text { da rede } \\
\text { pública de Picos, } \\
\text { Piauí. }\end{array}$ & $\begin{array}{c}28 \text { crianças com } \\
\text { idade de } 3 \text { a } 6 \\
\text { anos. }\end{array}$ & $\begin{array}{c}\text { Ascaris lumbricoides }(71,4 \%), \\
\text { Ancilostomídeos }(64,5 \%), \\
\text { Fasciola hepática }(42,9 \%), \\
\text { Strongyloides stercoralis } \\
(25,0 \%), \\
\text { Baladium coli }(21,4 \%), \\
\text { Enterobius vermicularis } \\
(14,2 \%), \\
\text { Entamoeba histolytica/dispar } \\
(10,7 \%), \\
\text { Taenia } \text { ssp. }(10,7 \%), \\
\text { Trichuris trichura }(3,5 \%) .\end{array}$ & $92,8 \%$ & $\begin{array}{l}\text { Centrífugo- } \\
\text { Sedimentação } \\
\text { pelo } \\
\text { Formaldeido- } \\
\text { Éter. }\end{array}$ \\
\hline Piauí & $\begin{array}{l}\text { Sousa, } \\
\text { Costa e } \\
\text { Vieira } \\
(2018)\end{array}$ & $\begin{array}{c}\text { Analisar a } \\
\text { prevalência de } \\
\text { enteroparasitas em } \\
\text { populares atendidos } \\
\text { no laboratório } \\
\text { municipal de Buriti } \\
\text { dos Lopes-PI entre o } \\
\text { período de fevereiro } \\
\text { a outubro de } 2017 \text {, } \\
\text { demonstrando os } \\
\text { parasitas mais } \\
\text { frequentes na } \\
\text { população, agrupados } \\
\text { por sexo e faixa } \\
\text { etária, com intuito de } \\
\text { verificar a quantidade } \\
\text { de pacientes } \\
\text { infectados com } \\
\text { enteroparasitas. }\end{array}$ & $\begin{array}{c}511 \text { laudos com } \\
\text { faixa etária de } 0 \text { a } \\
90 \text { anos }\end{array}$ & $\begin{array}{l}\text { Endolimax nana }(36,3 \%), \\
\text { Ascaris lumbricoides }(1,9 \%), \\
\text { poliparasitismo }(24,0 \%)\end{array}$ & $41,0 \%$ & $\begin{array}{l}\text { Hoffman, } \\
\text { Pons e Janer. }\end{array}$ \\
\hline $\begin{array}{l}\text { Rio Grande } \\
\text { do Norte }\end{array}$ & $\begin{array}{l}\text { Silva, } \\
\text { Fernandes e } \\
\text { Fontes- } \\
\text { Dantas } \\
(2017)\end{array}$ & $\begin{array}{c}\text { Identificar as } \\
\text { principais espécies } \\
\text { causadoras de } \\
\text { enteroparasitoses que } \\
\text { afetam a população } \\
\text { do bairro Cidade da } \\
\text { Esperança no } \\
\text { município de } \\
\text { Natal/RN que foram } \\
\text { atendidas pelo } \\
\text { Sistema Único de } \\
\text { Saúde (SUS), } \\
\text { contribuindo para o } \\
\text { conhecimento } \\
\text { epidemiológico das } \\
\text { parasitoses, além de } \\
\text { propor medidas de } \\
\text { erradicação das } \\
\text { mesmas ressaltando }\end{array}$ & $\begin{array}{l}2.394 \text { pacientes } \\
\text { atendidos na } \\
\text { Policlínica de } \\
\text { todas as faixas } \\
\text { etárias. }\end{array}$ & $\begin{array}{c}\text { Entamoeba coli }(46,9 \%), \\
\text { Entamoeba histolytica }(1,4 \%), \\
\text { Endolimax nana }(7,0 \%), \\
\text { Ancilostomídeos }(12,3 \%), \\
\text { Ascaris lumbricoides }(28,4 \%), \\
\text { Giardia lamblia }(3,1 \%), \\
\text { Iodamoeba butschlii }(0,5 \%) .\end{array}$ & $22,5 \%$ & $\begin{array}{l}\text { Hoffman, } \\
\text { Pons e Janer. }\end{array}$ \\
\hline
\end{tabular}




\begin{tabular}{|c|c|c|c|c|c|c|}
\hline & & $\begin{array}{l}\text { sua relevância em } \\
\text { questões de saúde. }\end{array}$ & & & & \\
\hline Sergipe & $\begin{array}{l}\text { Vasconcelos } \\
\text { et al. }(2016)\end{array}$ & $\begin{array}{l}\text { Investigar em uma } \\
\text { amostragem humana } \\
\text { a prevalência de } \\
\text { enteroparasitoses no } \\
\text { quadriênio de } 2007 \text { a } \\
2010 \text { em Aracaju, } \\
\text { SE. }\end{array}$ & $\begin{array}{l}153.912 \text { laudos de } \\
3 \text { laboratórios nos } \\
\text { anos de } 2007 \text { a } \\
2010 \text { de todas as } \\
\text { faixas etárias. }\end{array}$ & $\begin{array}{c}\text { Ascaris lumbricoides } \\
(55,6 \%), \text { Ancilostomídeos } \\
(22,4 \%), \text { Trichuris trichiura } \\
(15,1 \%), \\
\text { Enterobius vermicularis } \\
(3,8 \%), \text { Hyminolepis } \\
\text { nana }(2,0 \%), \text { Strongyloides } \\
\text { stercoralis }(0,9 \%), \text { Giardia } \\
\text { lamblia }(55,2 \%), \text { Entamoeba } \\
\text { histolytica/Entamoeba díspar } \\
(44,7 \%) .\end{array}$ & $49,3 \%$ & $\begin{array}{l}\text { Método não } \\
\text { informado. }\end{array}$ \\
\hline
\end{tabular}

Fonte: Autores.

\section{Bahia (BA)}

Carvalho et al. (2016) encontraram uma pequena predominância de sexo masculino $(57,3 \%)$ ao feminino $(42,7 \%)$, mas não foi avaliado estatisticamente. Constataram também a elevação progressiva da prevalência de parasitos intestinais dos indivíduos até os 11 anos, idade a qual atingiu o pico com 18,8\%, e queda abrupta e progressiva a partir dos 12 anos, atingido 2,6\% nos jovens com menos de 18 anos (Carvalho et al., 2016).

Lazzari et al. (2019) perceberam que não houve diferença estatística na prevalência de enteroparasitoses entre os sexos. Crianças (2 - 10 anos) e adolescentes (11 - 20 anos) evidenciaram 18,0\% e 3,0\%, respectivamente. No entanto, a faixa etária que predominou a positividade do exame coproscópico foi a população adulta jovem (21-40 anos) (Lazzari et al., 2019).

Glier et al. (2019), constataram que a prevalência de parasitos entre os gêneros foi maior entre os meninos (Glier et al., 2019). Já no município de Malhada- BA, encontraram que faixa etária com maior prevalência foi entre 5 a 12 anos, predominando no sexo masculino. Analisando especificamente a prevalência em relação ao sexo, há uma predominância no sexo feminino (Rosine, Rosine, Ribeiro \& Schröder, 2018).

\section{Pernambuco (PE)}

Cardozo, Mendes, França, Simonetti e Cordeiro (2018), identificaram protozoários comensais não patogênicos, patogênicos e helmintos, predominando nos adultos. Em crianças e adolescentes (0-17 anos) ocorreu pequena diminuição, de 38,0\% em 2015 para 37,8\% em 2016 (Cardozo et al., 2018).

Silva e Rocha (2019), encontraram uma frequência entre as crianças de 0 a 11 anos de $22,8 \%$ de positividade, porém observou-se predomínio dos casos em adolescentes entre 12 e 18 anos (24,7\%). Considerando apenas o sexo, a maior prevalência foi nas mulheres $(54,7 \%)$ (Silva \& Rocha, 2019).

\section{Maranhão (MA)}

Santos, Campos e Firmo (2020) verificaram que a maior ocorrência de parasitos intestinais foi na faixa de 0-10 anos (22,0\%), seguida pela faixa etária de 11-20 anos (21,0\%). Os resultados mostram predomínio das infecções causadas pelos protozoários $(76,0 \%)$ frente aos helmintos $(24,0 \%)$. Quanto ao sexo, o feminino foi mais frequente com 74,0\% dos positivos (Santos et al., 2020).

Oliveira et al. (2019) encontraram que a maior prevalência foi do sexo feminino. Alunos de escolas peri-urbanas apresentaram mais parasitismo do que os de escolas das áreas urbanas. Foi visto que 77,3\% das crianças parasitadas possuíam responsáveis com ensino fundamental incompleto (Oliveira et al., 2019).

Silva, Carvalho e Firmo (2016) compararam a ocorrência de parasitoses intestinais em crianças de duas comunidades da zona rural, Alto dos Cearenses e Assentamento, sendo a primeira mais próxima da zona urbana de Paulo Ramos-MA. Nota-se 
um resultado elevado para parasitoses na comunidade Assentamento, por ser uma região mais vulnerável devido suas condições de vida, saneamento básico e higiene, enquanto o Alto dos Cearenses, por estar mais próximo da zona urbana e possuir melhores condições socioeconômicas e demográficas apresentou menor número de casos positivos. Quanto à faixa etária, maior parte das crianças possuíam 5 e 6 anos no Assentamento (33,3\%). No Alto dos Cearenses foi maior entre 7 a 8 anos e 11 a 12 anos (ambas com 23,8\%). No Assentamento, a prevalência foi do sexo masculino (61,9\%) e no Alto dos Cearenses, feminino (66,7\%) (Silva, Carvalho \& Firmo, 2016), enquanto em São Luís foi observado que as duas escolas estudadas tiveram maior positividade no sexo feminino (Sá-Silva, Nunes, Monroe, Leite \& Santos, 2015).

Melo, Ericeira, Oliveira, Rocha e Firmo (2015) identificaram parasitos intestinais em laudos parasitológicos de fezes e desses, $230(31,8 \%)$ pertenciam a crianças entre 0 e 10 anos, porém o artigo não abordou o número de positivos em cada faixa etária (Melo et al., 2015).

Sousa et al. (2019) observaram o predomínio de protozoários, com $61,5 \%$ dos casos positivos; enquanto helmintos estavam em 38,4\% dos casos. Houve predomínio do sexo masculino (68,4\%) (Souza et al., 2019). Resultado encontrado também por Gomes et al. (2016) observando que 54,5\% eram do sexo masculino e 63,6\% dos seus pais não sabiam responder o que eram parasitoses intestinais (Gomes et al., 2016).

Rodrigues, Gomes, Lima e Nascimento (2018) deparam-se com infecção por helminto em 13,95\% dos exames, por protozoário em $86,0 \%$ e por duas espécies em $13,9 \%$. Foi visto que quanto maior a idade da mãe, reduz-se em $8 \%$ a probabilidade de a criança ser infectada por parasitos, enquanto que à medida que a mãe tem mais conhecimentos sobre os sintomas, há chances de redução de $16 \%$ nos casos (Rodrigues et al., 2018).

\section{Ceará (CE)}

Maia, Hassum e Valladares (2015) apresentaram que as UBSs localizadas na zona rural tiveram 57,3\% dos casos positivos e as da região urbana e áreas descobertas obtiveram $26,1 \%$ e $16,6 \%$ do total, respectivamente. A maior frequência ocorreu no sexo masculino. Em relação à idade, $20,1 \%$ das crianças tiveram resultados positivos, já dentre os adolescentes representaram 27,7\% de positividade (Maia et al., 2015). Enquanto Lima, Maia, Hassum, Valladares e Freitas (2015) observaram que as crianças foram responsáveis por 32,5\% dos casos positivos, enquanto os adolescentes por 15,0\% (Lima et al., 2015).

Asevedo, Andrade, Alves e Barbosa (2017) constaram que o sexo masculino foi mais prevalente $(54,3 \%)$ e nas crianças até 10 anos, observou-se prevalência de 22,9\% (Asevedo et al., 2017). Enquanto Santos, Nascimento, Cristo e Vandesmet (2016) realizaram o estudo que observou a maior prevalência parasitária na faixa etária de 0 a 13 anos (50,0\%). A maior prevalência de anemia associada ou não a parasitose aconteceu na faixa etária de 0 a 13 anos (8,3\%). Destacou-se que há uma associação significativa entre anemia e parasitoses intestinais (Santos et al., 2016).

Maia, Valladares e Hassum (2016), constatou-se que, entre 2009 e 2014, houve uma redução média anual significativa, de 2,4\% ao ano da prevalência de parasitoes intestinais. Constatou-se que 19,7\% das crianças testaram positivo para enteroparasitoses entre 2009 e 2014 no município em questão, enquanto os adolescentes representaram 20,4\% (Maia et al., 2016).

Almeida, Souza, Mourão e Pantoja (2017) depararam-se com maior positividade entre o sexo feminino (61,4\%). Em relação à faixa etária, constatou-se que de 0 a 11 anos houve uma maior prevalência de Endolimax nana (11,2\%) (Almeida et al., 2017). Já Pereira et al. (2018), encontraram uma prevalência maior de parasitoses em crianças do sexo masculino $(63,2 \%)$ (Pereira et al., 2018). 


\section{Alagoas (AL)}

Silva, Silva e Rocha (2018), constatou-se que a faixa etária de 0 a 9 anos apresentou uma prevalência de 17,0\%, enquanto a de 10 a 19 anos apresentou 12,0\%. As infecções protozoóticas foram predominantes, com 98,3\% dos casos, contra 1,6\% dos casos para helmintos (Silva et al., 2018).

\section{Paraíba (PB)}

Silva, Andrade, Cavalcante, Lima e Freitas (2018) observaram que dentre as amostras positivas, o gênero masculino apresentou maior ocorrência com 59,3\% de infectados (Silva \& Andrade et al., 2018). Enquanto Gonçalves, Fernandes, Medeiros e Oliveira (2016) encontraram um predomínio de infectados no sexo feminino $(76,0 \%)$. A faixa etária com maior prevalência foi de 0-10 anos (29,0\%) (Gonçalves et al., 2016).

Dias et al. (2017) realizaram estudo durante 3 anos e acreditam que houve diminuição nos números devido às intervenções que realizaram durante a pesquisa. As prevalências anuais foram de 61,7\% em 2013, 53,1\% em 2014 e 50,7\% em 2015. O grupo etário com maior frequência de infecção por enterparasitoses foi de 1-10 anos (Dias et al., 2017).

Sales, Queiroga, Olinda e Pedraza (2015) observaram que os dados apontam maiores chances de infestação por Entamoeba coli e Entamoeba histolytica e de poliparasitismo em crianças que frequentavam creches cinco dias na semana e, também, em crianças que frequentavam creches com higiene deficiente (Sales et al., 2015).

Oliveira e Barbosa (2019) depararam-se com o gênero feminino mais predominante (74,0\%). Na faixa etária de 0-9 anos, apenas uma amostra foi positiva (2,9\%) e na faixa de 10-19 anos encontrou-se 20,0\% dos casos positivos (Oliveira \& Barbosa, 2019).

Soares et al. (2016) rastrearam crianças de uma creche pública e faixa etária foi formada por crianças de 2 a 5 anos e o gênero mais acometido foi o masculino (60,9\%) (Soares et al., 2016).

\section{Piauí (PI)}

Leite, Neto, Sátiro, Fonseca e Ventura (2018), verificaram que o percentual de crianças contaminadas foi maior na faixa etária de 0 a 6 anos com 52,4\% dos casos e 47,6\% entre 7-12 anos, mas estatisticamente a diferença não foi considerada relevante. Quanto ao gênero, foi maior o número de infecções no sexo feminino $(53,5 \%)$, mas sem diferenças estatísticas. No estudo, foi possível identificar que houve uma maior ocorrência de parasitoses intestinais no período chuvoso (55,31\%) (Leite et al., 2018).

Sampaio e Barros (2017) depararam-se com uma prevalência maior no sexo masculino. Já em relação à faixa etária não houve positividade em menores de 5 anos e 21,7\% foi positivo entre 6-15 anos (Sampaio \& Barros, 2017).

Sousa, Costa e Vieira (2018) observou que o gênero feminino foi prevalente $(61,0 \%)$ e a faixa etária mais parasitada foi entre 0 a 10 anos (32,0\%), seguida da faixa de 11 a 20 anos com 22,0\% dos casos (Sousa et al., 2018).

\section{Rio Grande do Norte (RN)}

Silva, Fernandes e Fontes-Dantas (2017), reconheceram que o sexo feminino foi mais prevalente $(65,0 \%)$. Na faixa etária das crianças, $11,0 \%$ foram positivas (Silva et al., 2017).

\section{Discussão}

A América Latina geralmente apresenta uma média de 30 a 53\% de infecção e destes, quase 46 milhões são crianças e adolescentes. O nordeste brasileiro ainda possui altas taxas de prevalência das enteroparasitoses (Bragagnollo et al., 2018; Lima, Mendonça, Dantas, Brandão \& Medeiros, 2013). As prevalências encontradas foram variadas, com uma média 
aritmética de $37,7 \%$ de positividade e uma mediana de 37,9\%. Alguns estudos encontraram prevalências altas com $82,7 \%$ e 92,8\% (Pedraza, 2016; Ramos et al., 2019).

Em relação ao sexo, a positividade foi maior no feminino e isso pode ter sido influenciado pelos estudos em que se levaram em conta todas as faixas etárias, e não só as crianças. Alguns autores justificam essa maior positividade devido à maior procura pelos aparelhos de saúde, além de possuírem culturalmente um maior autocuidado e, assim, maior positividade (Almeida et al., 2017; Maia et al., 2016; Silva et al., 2017; Silva et al., 2018). Além disso, atribuem essa situação à maior exposição para a infecção parasitária nos trabalhos domésticos com utilização de água contaminada para limpeza da casa, dos alimentos, lavagem de utensílios e para a própria ingestão (Rosine et al., 2018; Sousa et al., 2018). Outra justificativa utilizada é que as mulheres estão em maior contato com creches e fraldas de bebês contaminados (Santos et al., 2020).

Nos estudos em que a maioria foi do sexo masculino tinham como justificativa o maior número de exames coprológicos realizados, que crianças do sexo masculino interagem mais que o feminino com os ambientes contaminados, andam descalços, não possuem hábitos higiênicos e, culturalmente, as brincadeiras permitem maior sujidade entre os meninos, além da desatenção aos cuidados à saúde (Carvalho et al., 2016; Maia et al., 2015; Pereira et al., 2018; Sampaio \& Barros, 2017; Silva \&Andrade et al., 2018; Soares et al., 2016).

As estimativas eram de 1,5 bilhões de pessoas infectadas com helmintos transmitidos pelo solo no mundo todo em 2014. Dessas, cerca de 269 milhões são de crianças em idade pré-escolar e 572 milhões em idade escolar. Na maioria dos países da América, a intensidade das infecções por helmintos transmitidas pelo solo é baixa ou moderada (World Health Organization, 2017).

De fato, alguns estudos avaliaram apenas a faixa etária das crianças, porém alguns realizaram análise de prontuários de todas as idades e, ainda assim, as mais acometidas foram as crianças de 0 a 12 anos. Isso é explicado provavelmente pela imaturidade imunológica, aumento do número de crianças em creches em tempo integral, o que facilita a transmissão de enteroparasitoses via água/alimentos contaminados e aglomerações (Almeida et al., 2017; Gonçalves et al., 2016; Leite et al., 2018; Pereira et al., 2018; Sales et al., 2015; Sampaio \& Barros, 2019; Silva et al., 2016; Sousa et al., 2018). Ademais ocorre o desconhecimento dos princípios básicos de higiene e de maior exposição aos agentes devido ao intenso contato com o solo, pois é palco de muitas brincadeiras, dependerem de cuidados alheios, hábito de levar as mãos sujas à boca, falta de acesso aos serviços básicos de saúde e ausência de projetos de educação sanitária, e também, uma maior consciência higiênica dos adultos (Almeida et al., 2017; Golçalves et al., 2016; Ramos et al., 2019; Rosine et al., 2018; Santos et al., 2020; Silva et al., 2016; Silva \& Andrade et al., 2018; Sousa et al., 2018; Sousa et al., 2019).

As parasitoses intestinais nas crianças, especialmente na idade escolar, consistem em um fator agravante da má nutrição que pode gerar prejuízos no desenvolvimento físico e intelectual, além de poder ser acompanhado de diarreia crônica (Rosine et al., 2018).

Em todos os artigos em que se pesquisou protozoários e helmintos, encontrou-se maior prevalência de protozoários comensais não patogênicos, como o Entamoeba coli e o Endolimax nana. A presença de protozoários causadores ou não de doenças demonstra uma contaminação fecal-oral e, assim, pode ser indicador de saneamento inadequado ou inexistente e evidencia a necessidade de implementação de medidas preventivas (Asevedo et al., 2017; Maia et al., 2015; Oliveira \& Barbosa, 2019). Essa maior frequência pode ser devida principalmente à facilidade do processo de transmissão e que não necessita de estágio de maturação no solo, como os geohelmintos (Santos et al., 2020). Apesar de ser considerados comensais do intestino humano, o Entamoeba coli e o Endolimax nana estão associados a ocorrência de diarreia em crianças (Almeida $e t$ al., 2017).

O protozoário patogênico mais encontrado foi o Giardia lamblia e é causador da giardíase, que gera quadros assintomáticos até diarreia aguda, podendo evoluir para cronicidade acompanhada de esteatorreia, emagrecimento e síndrome 
da má absorção intestinal (Oliveira \& Barbosa, 2019). Também está relacionado à precariedade das condições sanitárias e de tratamento de água, bem como de alimentos contaminados com cistos infectantes desse parasito (Almeida et al., 2017).

A baixa prevalência de helmintos foi justificada pelo uso indiscriminado de anti-helmínticos que reduz a prevalência, mas não acaba com o ciclo epidemiológico, possibilitando novas reinfecções (Carvalho et al., 2016; Maia et al., 2016; Silva et al., 2018). Outro ponto levantado diz respeito ao método utilizado para detecção dos parasitos, pois a técnica de sedimentação espontânea utiliza apenas uma lâmina com amostra fecal e não leva em consideração a eliminação intermitente, assim, seria mais fidedigno a utilização de mais de um método de análise coproscópica (Asevedo et al., 2017; Maia et al., 2016; Sá-Silva et al., 2015). Ademais, percebeu-se que o clima semiárido de algumas regiões, como Piauí, Alagoas e Bahia, dificulta a disseminação helmíntica devido à baixa umidade no solo limitando a proliferação desses parasitos (Cardoso et al., 2020; Maia et al., 2016; Rosine et al., 2018; Sampaio \& Barros, 2017; Silva et al., 2018; Vasconcelos et al., 2016).

Ainda, foi relatado que na Bahia não se encontram a espécie Biomphalaria, hospedeiro intermediário do Schistosoma mansoni, e por esse motivo não foi encontrado infectados (Rosine et al., 2018). Porém, em Pernambuco, um estudo encontrou esse parasito como o principal helminto e está associado a diversos fatores, como condições sanitárias precárias, falta de práticas educativas em saúde, disseminação dos hospedeiros intermediários e a longevidade da própria doença (Silva \& Rocha, 2019).

O helminto mais prevalente no conjunto de todos os estudos foi o Ascaris lumbricoides e pode ser justificada pelo fato de os ovos deste parasito serem bastante resistentes e com capacidade de se manterem viáveis por longos períodos no ambiente (Santos et al., 2020). O verme adulto dessa espécie pode causar ação tóxica (quadros alérgicos como urticária), mecânica (obstrução intestinal, causando anorexia, vômitos, desidratação, eliminação de vermes pela boca, narinas e ânus) e espoliadora, podendo levar à subnutrição e retardo no desenvolvimento físico e mental (Dias et al., 2017; Pereira et al., 2018).

$\mathrm{Na}$ maioria dos estudos foram encontradas crianças biparasitadas ou poliparasitadas. Indivíduos com múltiplos parasitos podem apresentar infecções mais severas que indivíduos com infecções únicas (Asevedo et al., 2017; Glier et al., 2019; Gomes et al., 2016; Lazzari et al., 2019; Melo et al., 2015; Rosine et al., 2018; Sampaio \& Barros, 2017; Sá-Silva et al., 2015; Silva \& Andrade et al., 2018; Silva \& Rocha, 2019; Sousa et al., 2019).

Alguns estudos se depararam com uma maior prevalência na zona rural em comparação com a urbana, e da própria zona urbana em relação às suas periferias. Essas diferenças refletem as divergentes condições socioeconômicas, sanitárias e ambientais, uma vez que a cobertura de saneamento básico no Brasil ainda é uma problemática devido à escassez (Lima et al., 2015. Maia et al., 2015). Muitos utilizam água de poço, nascentes ou água direto da torneira e pode estar aliado à falta de limpeza dos reservatórios e a não utilização de água filtrada ou fervida, levando a maior incidência de parasitoses (Maia et al., 2016; Oliveira \& Barbosa, 2019; Ramos et al., 2019; Rosine et al., 2018). Em relação ao esgoto, um estudo levantou que 98\% dos estudados realizavam suas necessidades fisiológicas ao ar livre, o que favorece o ciclo biológico da maioria dos parasitos (Melo et al., 2015). Além disso, apontam a ausência ou ineficácia de assistência médica a este público (Lazzari et al., 2019; Pereira et al., 2018). Garantido na Assembleia Geral da ONU, em 2010, o acesso ao saneamento básico é um direito humano essencial e é necessário para diminuir a injustiça ambiental, gerando um local sadio, equilibrado e seguro (Lima et al., 2015).

Outra problemática diz respeito à falta de conhecimento da população adulta quanto às profilaxias das enteroparasitoses. Questionadas as mães, percebeu-se que não sabiam responder o que eram as parasitoses intestinais, mas disseram que poderiam adquirir parasitos através da água, terra e alimentos. Quando questionadas sobre as profilaxias responderam com "lavagem dos alimentos" e "não andar descalço". O parasito mais conhecido entre elas era a "lombriga", nome popular da espécie Ascaris lumbricoides. Evidenciou-se nesses estudos que o grau de escolaridade pode ter influenciado no desconhecimento das parasitoses (Gomes et al., 2016; Pereira et al., 2018; Rodrigues et al., 2018).

Quanto à saúde das crianças, percebeu-se uma associação significativa entre a presença de parasitose intestinal e 
anemia ferropriva (Santos et al., 2016). Outro estudo comparou duas comunidades e constatou que 100,0\% das crianças de uma delas estavam abaixo do peso adequado para a altura, e foi nessa comunidade em que houve a maior ocorrência de enteroparasitoses, e na outra, o índice de crianças com baixo peso observado foi de 57,0\% (Silva et al., 2016).

\section{Conclusão}

Foi possível constatar que a prevalência de parasitoses intestinais em crianças ainda é um problema na região do Nordeste brasileiro e permanece alta, indicando dificuldades no acesso à educação sanitária e no controle das infecções. Muitas crianças apresentaram poliparasitismo com associações entre helmintos e protozoários, o que também evidencia que as condições sócio-sanitárias podem ter relação direta com os casos. Mesmo com pequena diferença entre números e poucas variações estatísticas, o sexo feminino foi o mais acometido. Os protozoários mais prevalentes foram o Entamoeba coli e a Endolimax nana e o helminto de maior frequência foi o Ascaris lumbricoides, porém características dos ambientes podem influenciar a prevalência maior de protozoários do que de geohelmintoses. Foi possível associar, em alguns casos, a presença de parasitos e a má nutrição das crianças evidenciando a espoliação que sofrem. Chama a atenção o pequeno número de estudos encontrados em alguns estados, evidenciando a negligência com relação ao tema. Dessa maneira, fica evidente a necessidade de medidas que diminuam ou até eliminem processos de infecções, reinfecções e consequentemente, transmissões desses parasitos. E nesse contexto, enquadram-se como indispensáveis, diversas medidas profiláticas, tais como a realização dos exames parasitológicos de fezes pelo menos a cada seis meses, a higienização correta e frequente dos alimentos, a utilização de água tratada ou fervida, saneamento básico, tratamento dos infectados, manutenção de boas condições de higiene em todos os domicílios e peridomicílios, além da presença frequente de políticas de saúde pública que incentivem a realização constante de atividades educativas em saúde em todas as regiões mencionadas no estudo.

Com o objetivo de atingir uma maior abrangência em relação ao número de estudos, tem-se como perspectiva para trabalhos futuros a busca em outros indexadores, além do aumento do escopo para artigos brasileiros escritos em inglês e espanhol. Somado a isso, faz-se necessário a realização de pesquisas em torno de diferentes regiões do país tornando possível a comparação com os achados do presente artigo.

\section{Referências}

Almeida, M. A., Souza, J. C., Mourão, C. L. \& Pantoja, L. D. M. (2017). Prevalência de enteroparasitas na região metropolitana de Fortaleza, Ceará. Acta Biomedica Brasiliensia.8(2):91-100.

Asevedo, J. A. B., Andrade, F. P., Alves, T. W. B. \& Barbosa, V. S. A. (2017). Prevalência de parasitoses intestinais em crianças e adolescentes matriculadas em uma ONG do município de Orós - CE. II Congresso Brasileiro de Ciências da Saúde.

Bragagnollo, G. R., Godoy, P. C. G. T., Santos, T. S., Ribeiro, V. S., Morero, J. A. P. \& Ferreira, B. R. (2018). Intervenção educacional sobre enteroparasitoses: um estudo quase experimental. Revista Cuidarte. 9(1).

Brasil. (2010). Doenças infecciosas e parasitárias: guia de bolso. Departamento de Vigilância Epidemiológica. Brasília: Ministério da Saúde.

Brasil. (2005). Plano Nacional de Vigilância e Controle das Enteroparasitoses. Secretaria de Vigilância em Saúde.

Cardoso, A. B., Sousa, E. A., Silva, G. D., Campelo, P. N. G., Mendes, J. R., Ventura, M. C. S., Silva, D. F. M., Silva, J. \& Freire, S. M. (2020). Perfil epidemiológico-socioeconômico de enteroparasitoses em crianças de 03 A 10 anos em Teresina-PI. Brazilian Journal of Development. 6(3):11160-75.

Cardozo, T. G. D., Mendes, L. G. P., França, T. A. S., Simonetti, A. C. \& Cordeiro, R. P. (2018). Incidência de parasitoses intestinais em uma população assistida por um hospital público do agreste pernambucano. Repositório ASCES.

Carvalho, F. L., Souza, V. B., Jesus, J. M., Santos, I. P., Almeida, J. S., Pereira, J. S., Jesus, R. S., Silva, I. M. \& Amor, A. L. M. (2016). Enteroparasitos, indicadores socioculturais e de saúde em uma população de 0 a 18 anos do município de Santo Antônio de Jesus (Bahia)-período de 2010 a 2011 . Journal of Health \& Biological Sciences. 4(1):8-17.

Dias, L., Pequeno, I., Cavalcante, U., Silva, C., Lima, C. \& Freitas, F. S. (2017). Estudo coproparasitológico e epidemiológico de crianças e manipuladores de alimentos durante 3 anos em uma creche da Paraíba. Revista de epidemiologia e controle de infecção. 7(2). 
Furtado, L. F. V. \& Melo, A. C. F. L. (2011). Prevalência e aspectos epidemiológicos de enteroparasitoses na população geronte de Parnaíba, Estado do Piauí. Revista da Sociedade Brasileira de Medicina Tropical. 44(4):513-5.

Glier, J. S. P. C., Souza, D. C., Vitor, I. B. M., Silva, P. D. S., Silva, R. E. R., Dobrachinski, L. (2019). Prevalência de enteroparasitoses intestinais em crianças assistidas por uma organização não governamental (ONG) do município de Barreiras-BA: resultados parciais. Anais Eletrônico Cic. 17(17).

Gomes, S. C. S., Rodrigues, S. R., Silva, A. B., Arruda, A. K. S., Silva, N. M., Macedo, R. S., Lima, E. N. P. \& Ferreira, I. E. A. (2016). Educação em saúde como instrumento de prevenção das parasitoses intestinais no município de Grajaú-MA. Pesquisa em Foco. 21(1).

Gonçalves, S. A. A., Fernandes, H. M. B., Medeiros, C. I. S. \& Oliveira, A. A. (2016). Perfil enteroparasitológico dos pacientes atendidos em uma policlínica do Sertão da Paraíba, Brasil. Journal of Medicine and Health Promotion.1(3):302-312.

Grott, S. C., Hartmann, B., Franco, R. M. B. \& Goulart, J. A. G. (2016). Detecção de cistos de Giardia spp. e oocistos de Cryptosporidium spp. na água bruta das estações de tratamento no município de Blumenau, SC, Brasil. Revista Ambiente \& Água. 11(3):689-701.

Lazzari, F., Valéria, K., Oliveira, R. L. D. S., Dobrachiski, L., Stefanello, S. T. \& Mizdal, C. R. (2019). Prevalência de enteroparasitoses em pacientes do município de Luis Eduardo Magalháes-BA. Anais Eletrônico Cic. 17(17).

Leite, O. A. C., Neto, D. C. C., Sátiro, F. A. S., Fonseca, F. M. \& Ventura, C. Â. (2018). Ocorrência de enteroparasitos em crianças e a correlação com as estações seca e chuvosa, no município de Parnaíba, Piauí, Brasil. Revista Interdisciplinar. 11(4):42-9.

Lima, D. S., Mendonça, R. A., Dantas, F. C. M., Brandão, J. O. C. \& Medeiros, C. S. Q. (2013). Parasitoses intestinais infantis no nordeste brasileiro: uma revisão integrativa da literatura. Cadernos de Graduação - Ciências Biológicas e da Saúde. 1(2):71-80.

Lima, J. G. A., Maia, C. V. A., Hassum, I. C., Valladares, G. S. \& Freitas, M. J. C. (2015). Enteroparasitoses e saneamento básico em Limoeiro do Norte - CE. XIX Exposição de Experiências Municipais em Saneamento; 2015; Poços de Caldas-MG

Lins, Í. V. F., Soares, C. V. D., Costa, R., Soares, G. V. D., Duarte, A. B. S. \& Medeiros, J. S. (2016). Comparação entre o método da fita adesiva e o método de sedimentação espontânea para o diagnóstico de Enterobius Vermicularis. Journal of Biology \& Pharmacy and Agricultural Management. 12(4).

Maia, C., Hassum, I. C. \& Valladares, G. S. (2015). Parasitoses intestinais em usuários do sus em Limoeiro do Norte, Ceará, antes de expansão de sistema de esgotamento sanitário. Holos.2:98-109.

Maia, C. A., Valladares, G., Hassum, I. (2016). Distribuição espacial do enteroparasitismo em usuários do sistema único de saúde, em Limoeiro do Norte, Ceará, Brasil, entre 2009 e 2014. Embrapa Meio-Norte-Artigo em periódico indexado (ALICE).

Melo, A., Ericeira, F. V., Oliveira, N. D., Rocha, J. R. \& Firmo, W. C. A. (2015). Ocorrência de parasitos intestinais em laudos parasitológicos de fezes de um laboratório privado do município de Bacabal-MA. Enciclopédia Biosfera, Centro Científico Conhecer-Goiânia. 11(21):201.

Menezes, V. F. P., Medeiros, N. da S., \& Dani, C. (2012). Prevalência de Enteroparasitoses em Escolares: Uma Revisão do Perfil Encontrado nas Diferentes Regiões do Brasil. Revista Brasileira Multidisciplinar, 15(2), 7-18.

Monteiro, A. M. C., Silva, E. F., Almeida, K. S., Sousa, J. J. N., Mathias, L. A., Baptista, F. \& Freitas, F. L. C. (2009). Parasitoses intestinais em crianças de creches públicas localizadas em bairros periféricos do município de Coari, Amazonas, Brasil. Revista de Patologia Tropical. 38(4):284-90.

Mylius, L. C., Spalding, S., Sopelsa, A. M. I., Raffin, R. P., Silva, V. C. L. \& Ponte, C. I. R. V. (2003). Perfil parasitológico de crianças de vilas periféricas de Porto Alegre, RS. Revista Brasileira de Farmácia. 84(1):29-31.

Nicoli, B. M., Kunzendorff, B. A., Luz, F. A., Martins, K. G., Randow, R. M. (2018). Amebíase: uma revisão bibliográfica e visão epidemiológica. Anais do Seminário Científico do UNIFACIG.

Oliveira, A. L. \& Barbosa, V. S. A. (2019). Prevalência de enteroparasitoses em usuários do laboratório de análises clínicas de Araruna-PB. Revista saúde \& ciência online. 7(3):05-22.

Oliveira, A. S. S. S., Silva, B. E. S., Cunha, E. A., Macedo, J. L., Rodrigues, A. C. E., Assunção, M. J. S. M. \& Azevêdo, C. A. S. (2019). Enteroparasitoses em escolares da rede pública municipal. Research, Society and Development. 8(4):17.

Organization WH. (2017). Integrating neglected tropical diseases into global health and development: fourth WHO report on neglected tropical diseases: World Health Organization.

Pedraza, D. F. (2016). Saúde e nutrição das crianças assistidas em creches públicas do município de Campina Grande, Paraíba. Cadernos Saúde Coletiva. 24(2):200-8.

Pedroso, R. F. \& Amarante, M. K. (2006). Giardíase: Aspectos Parasitológicos e Imunológicos. Biosaúde. 8(1):61-71.

Pereira, G., Ribeiro, C., Costa, I., Silva, J., Calado, L., Nunes, B., Aguiar, J., Rodrigues, F. \& Mota, M. (2018). Prevalência de infecções parasitárias intestinais oriundas de crianças residentes em áreas periféricas, município de Juazeiro do Norte-Ceará. Revista Interfaces: Saúde, Humanas e Tecnologia. 5(14):21-7.

Ramos, A. E., Silva, T. T. R., Oliveira, Y. R., Silva, P. H., Abreu, M. C., Marques, M. M. M., Silva, E. L., Pinheiro, T. G., Sousa, A. F. \& Pacheco, A. C. L. (2019). Avaliação do Consumo Alimentar, Estado Nutricional e Ocorrência de Enteroparasitos em Crianças Pré-Escolares no Município de Picos-Piauí, Nordeste Brasileiro. Ensaios e Ciência. 23(3):268-72.

Rodrigues, S. R., Gomes, S. C. S., Lima, R. J. C. P. \& Nascimento, J. X. P. T. (2018). Projeto Parasitoses Intestinais em crianças: prevalência e fatores associados. Revista Ciência em Extensão. 14(3):64-78.

Rosine, G. D., Rosine, I. O., Ribeiro, F. \& Schröder, N. T. (2018). Prevalência de parasitose intestinal em uma comunidade quilombola do semiárido baiano. Aletheia. 51(l 1 e 2). 
Sales, M. C., Queiroga, C. D., Olinda, R. A. \& Pedraza, D. F. (2015). Associação entre características higiênicas de creches públicas e frequência de enteroparasitoses em crianças institucionalizadas de Campina Grande, Paraíba, Brasil. Revista Cereus. 7(2):187-.

Sampaio, J. P. \& Barros, V. C. (2017). Prevalência de enteroparasitoses em pacientes atendidos em uma unidade mista de saúde de Beneditinos-PI. Jornal Interdisciplinar de Biociências. 2(1):6-10.

Santos, J. C. S., Campos, E. J. L. L. \& Firmo, W. C. A. (2020). Parasitas intestinais em pacientes atendidos em um laboratório público do município de Alto Alegre do Pindaré-Ma. Journal of Biology \& Pharmacy and Agricultural Management. 16(1).

Santos, J. G. A., Nascimento, P. A. C., Cristo, J. S. \& Vandesmet, V. C. S. (2016). Anemia associada às parasitoses intestinais de pacientes atendidos em um laboratório de análises clínicas no município de Juazeiro do Norte-CE. Revista Interfaces: Saúde, Humanas e Tecnologia.

Sá-Silva, J. R., Nunes, D. S., Monroe, N. B., Leite, P. R. \& Santos, W. H. L. (2015). Incidência de enteroparasitos em alunos do ensino fundamental (2º ao $5^{\circ}$ anos) da rede pública municipal de São Luís-MA. Pesquisa em Foco. 20(1).

Silva, A. A., Silva, P. V. R. \& Rocha, T. J. M. (2018). Parasitos intestinais: frequência e aspectos epidemiológicos em usuários de um laboratório particular. Diversitas Journal. 3(2):245-56.

Silva, E. F., Silva, E. B., Almeida, K. S., Sousa, J. J. N. \& Freitas, F. L. C. (2009). Enteroparasitoses em crianças de áreas rurais do munícipio de Coari,. Revista De Patologia Tropical / Journal of Tropical Pathology, 38(1), 35-44.

Silva, E. P., Carvalho, W. R. C. \& Firmo, W. D. C. A. (2016). Estudo comparativo da ocorrência de parasitoses intestinais em crianças de duas comunidades da zona rural de Paulo Ramos-MA, Brasil. Revista UNINGÁ Review. 27(2).

Silva, J. D. R. \& Rocha, T. J. M. (2019) Frequência de helmintos segundo os dados do programa de controle da esquistossomose no município de Xexéu, Pernambuco. Journal of Health \& Biological Sciences. 7(3):253-7.

Silva, M. M. C., Fernandes, J. C. \& Fontes-Dantas, F. L. (2017). Incidência de parasitoses intestinais diagnosticadas em regiões carentes de uma região metropolitana. Carpe diem: Revista Cultural e Científica do UNIFACEX. 15(1):80-90.

Silva, T. O., Andrade, T. S. O., Cavalcante, U. M. B., Lima, C. M. B. L., \& Freitas, F. I. S. (2018). Enteroparasitos em Crianças de Creches da Cidade de João Pessoa-PB. Revista Cereus.10.

Soares, C. V. D., Albino, S. L., Costa, R., Duarte, A. B. S., Queiroga, C. D. \& Medeiros J. S. (2016). Prevalência de enteroparasitoses em crianças de uma creche pública no município de Campina Grande. Journal of Biology \& Pharmacy and Agricultural Management. 12(4)

Sousa, A. C. P., Costa, L. N. G. \& Vieira, J. M. S. (2018). Prevalência de enteroparasitas em indivíduos atendidos no Laboratório Municipal de Buriti dos Lopes, Piauí, Brasil. RBAC. 50(2):184-8.

Sousa, F. C. A., Siqueira, H. D. S., Siqueira, F. F. F. S., Oliveira, E. H., Verde, R. M. C. L., Miranda, R. N. C., Miranda, N. M. R. S., Rodrigues, L. A. S., Silva, W. C., Coelho, L. N. \& Maia, N. M. F. S. (2019). Prevalência de parasitoses intestinais em crianças de uma escola pública municipal. Revista Enfermagem Atual InDerme. 90(28).

Souza, Luciana Karine de. (2019). Pesquisa com análise qualitativa de dados: conhecendo a Análise Temática. Arquivos Brasileiros de Psicologia, 71(2), 5167.

Vasconcelos, C. S., Almeida, M., Brito, R., Guimarães, A., Boaventura, R. \& Brito, A. (2016). Enteroparasitoses humanas em Aracaju, SE. RBAC. 48(4):35662 .

Vaz, A. C. R. L. (2014). Aspectos imunológicos na infecção por ascaris lumbricoides [Mestrado on the Internet]. Instituto Superior de Ciências da Saúde Egas Moniz. Caracterização Ascaris lumbricoides: profilaxia; p. 20.

Weber, B. V., Simon, C., Pause, C., Perinazzo, J., Bazana, L. C. G., Perassolo, P. C., Vesz, V., Stadlober, C. B. \& Pedroso, D. (2012). Brincar e aprender com a Parasitologia. Revista Trajetória Multicursos-FACOS/CNEC Osório.

Zaiden, M. F., Santos, B. O., Cano, M. A. T., \& Nascif Júnior, I. A. (2008). Epidemiologia das parasitoses intestinais em crianças de creches de Rio VerdeGO. Medicina (Ribeirão Preto), 41(2), 182-187. 